\title{
A high-affinity human TCR-like antibody detects celiac disease gluten pMHC complexes and inhibits T-cell activation
}

Rahel Frick ${ }^{1,2, \dagger, 8}$, Lene S. Høydahl $1^{1,2,3, \dagger}$, Jan Petersen ${ }^{4,5, \dagger}$, M. Fleur du Pré ${ }^{1,3}$, Shraddha Kumari ${ }^{6}$, Grete Berntsen ${ }^{6}$, Alisa E. Dewan ${ }^{1,3}$, Jeliazko R. Jeliazkov ${ }^{7}$, Kristin S. Gunnarsen ${ }^{1,2}$, Terje Frigstad ${ }^{6}$, Erik S. Vik ${ }^{6}$, Carmen Llerena ${ }^{4}$, Knut E.A. Lundin ${ }^{1,3,8}$, Sheraz Yaqub ${ }^{9}$, Jørgen Jahnsen ${ }^{10,11}$, Jeffrey J. Gray ${ }^{7,12,13}$, Jamie Rossjohn ${ }^{4,5,14}$, Ludvig M. Sollid $^{1,3}$, Inger Sandlie ${ }^{1,2}$, Geir Åge Løset ${ }^{1,2,6, *}$

${ }^{1}$ Centre for Immune Regulation and Department of Immunology, University of Oslo and Oslo University Hospital, Norway.

${ }^{2}$ Centre for Immune Regulation and Department of Biosciences, University of Oslo, Norway.

${ }^{3} \mathrm{KG}$ Jebsen Coeliac Disease Research Centre, University of Oslo, Norway.

${ }^{4}$ Infection and Immunity Program, Department of Biochemistry and Molecular Biology, Biomedicine Discovery Institute, Monash University, Clayton, Victoria, Australia.

${ }^{5}$ Australian Research Council Centre of Excellence for Advanced Molecular Imaging, Monash University, Clayton, Victoria, Australia.

${ }^{6}$ Nextera AS, Oslo, Norway.

${ }^{7}$ Program in Molecular Biophysics, Johns Hopkins University, Baltimore, Maryland, USA.

${ }^{8}$ Department of Gastroenterology, Oslo University Hospital-Rikshospitalet Oslo, Norway.

${ }^{9}$ Department of Gastrointestinal Surgery, Oslo University Hospital-Rikshospitalet, Oslo, Norway.

${ }^{10}$ Department of Gastroenterology, Akershus University Hospital, Lørenskog, Norway.

${ }^{11}$ Institute of Clinical Medicine, University of Oslo, Oslo, Norway.

${ }^{12}$ Department of Chemical and Biomolecular Engineering and Institute of NanoBioTechnology, Johns Hopkins University, Baltimore, MD, USA.

${ }^{13}$ Sidney Kimmel Comprehensive Cancer Center, Johns Hopkins School of Medicine, Baltimore, MD, USA.

${ }^{14}$ Institute of Infection and Immunity, Cardiff University School of Medicine, Heath Park, Cardiff, United Kingdom.

†These authors contributed equally. 
§Present address: Department of Chemical and Biomolecular Engineering, Johns Hopkins University, Baltimore, MD, USA.

*For correspondence: galoset@nextera.no.

One Sentence Summary: An engineered human TCR-like antibody blocks gluten-dependent activation of primary celiac T-cells in vitro and in HLA-DQ2.5 humanized mice. 


\begin{abstract}
Antibodies specific for peptides bound to human leukocyte antigen (HLA) molecules are valuable tools for studies of antigen presentation and may have therapeutic potential. Here, we generated human T-cell receptor (TCR)-like antibodies towards the immunodominant signature gluten epitope DQ2.5-glia- $\alpha 2$ in celiac disease (CeD). Phage display selection combined with secondary targeted engineering was used to obtain highly specific antibodies with picomolar affinity. The crystal structure of a Fab fragment of the lead antibody 3.C11 in complex with HLADQ2.5:DQ2.5-glia- $\alpha 2$, revealed a binding geometry and interaction mode highly similar to prototypic TCRs specific for the same complex. Assessment of CeD biopsy material confirmed disease specificity and reinforced the notion that abundant plasma cells present antigen in the inflamed CeD gut. Further, 3.C11 specifically inhibited activation and proliferation of gluten-specific $\mathrm{CD}^{+} \mathrm{T}$ cells in vitro and in HLA-DQ2.5 humanized mice, suggesting a potential for targeted intervention without compromising systemic immunity.
\end{abstract}

\title{
Introduction
}

Antibodies with specificity for peptide MHC (pMHC), so called T-cell receptor (TCR)-like antibodies, have been successfully used to detect and quantify peptide presentation on cells and several studies suggest therapeutic potential by different modes of action, including inhibition of pathogenic $\mathrm{T}$ cells and killing mechanisms to delete antigen-presenting cells (APCs) (1-3). As soluble reagents, antibodies are often preferred over TCRs due to their increased stability and higher affinity (4-8). We have previously and in this study generated TCR-like antibodies specific for pMHC complexes implicated in celiac disease (CeD) (9).

$\mathrm{CeD}$ is an inflammatory autoimmune-like condition of the small intestine caused by immune reactions to dietary gluten proteins (10). The disease is driven by $\mathrm{CD}^{+} \mathrm{T}$ cells that recognize deamidated gluten peptides in the context of the disease-associated HLA-DQ molecules HLA-DQ2.5 (DQA1*05 - DQB1*02), HLA-DQ2.2 $(D Q A 1 * 02: 01 / D Q B 1 * 02: 01)$, and HLA-DQ8 (DQA1*03/DQB1*03:02) (11). Out of these HLA variants, HLADQ2.5 is the most strongly associated with $\mathrm{CeD}$ and is detected in around $90 \%$ of $\mathrm{CeD}$ patients compared to approximately $20 \%$ in healthy controls (11). Deamidation of gluten peptides is mediated by the enzyme 
transglutaminase 2 (TG2) and results in conversion of Gln to negatively charged Glu at specific sites in polypeptides transforming proteolytically stable, but immunologically inert, peptides into pathogenic T-cell epitopes $(12,13)$. A range of gluten T-cell epitopes has been characterized, but four immunodominant epitopes derived from $\alpha$-gliadin and $\omega$-gliadin are particularly prominent in the context of HLA-DQ.2.5, namely DQ2.5glia- $\alpha$ 1a (PFPQPELPY), DQ2.5-glia- $\alpha 2$ (PQPELPYPQ), DQ2.5-glia- $\omega 1$ (PFPQPEQPF), and DQ2.5-glia- $\omega 2$ (PQPEQPFPW). T-cell responses against these epitopes are found in the majority of HLA-DQ2.5 ${ }^{+}$patients and are considered to orchestrate tissue destruction in the small intestine and autoantibody production (14-16). The only currently available treatment for $\mathrm{CeD}$ is lifelong adherence to a gluten-free diet. Development of alternative treatments is sought after due to poor patient compliance with the dietary restrictions, unavailability of strictly gluten-free food and the feared transformation of uncomplicated $\mathrm{CeD}$ to refractory $\mathrm{CeD}(17,18)$. Whilst it is still unclear how the destructive $\mathrm{T}$ cells emerge in $\mathrm{CeD}$, recent findings have suggested a role for environmental factors including possible $\mathrm{T}$ cell cross-reactivity with microbial antigens $(19,20)$ and highlighted a need for further investigations into the roles of different MHC-presented antigens in CeD.

Recently, we reported the generation and use of antibodies selected on HLA-DQ2.5:DQ2.5-glia- $\alpha 1$. We surprisingly found that gut plasma cells (PCs) are the most abundant gluten peptide-presenting cells in the inflamed small intestine of CeD patients and that they express both HLA class II and T-cell co-stimulatory molecules (9).

In the current study, we describe the generation and affinity maturation of human TCR-like antibodies specific for HLA-DQ2.5 in complex with DQ2.5-glia- $\alpha 2$. Importantly, we have previously shown that this complex elicits a prototypic signature CeD T-cell response which appears to be shared across all patients $(21,22)$. Our strategy was based on phage display selection of a fully human naïve antibody library combined with secondary complementarity determining region (CDR)-targeted optimization and gave rise to highly specific binders with picomolar monomeric affinities towards HLA-DQ2.5:DQ2.5-glia- $\alpha 2$. The co-crystal structure of a Fab fragment of the lead antibody 3.C11 in complex with HLA-DQ2.5-glia- $\alpha 2$ revealed an approximately diagonal docking geometry with respect to the peptide and a footprint highly similar to prototypic CeD patient derived TCRs with the same specificity. The antibodies readily stained a population of PCs from inflamed CeD lamina propria biopsy 
material, whereas the scarce $\mathrm{CD} 11 \mathrm{c}^{+}$and $\mathrm{CD} 14^{+}$dendritic cells (DCs) and macrophages (Mfs) from the corresponding material stained less prominently. These results confirm and extend our previous observation on the central role of the B-cell compartment in this tissue (9). We further observed potent and strictly HLA and epitope-dependent inhibition of T-cell activation, both using $\mathrm{CeD}$ derived $\mathrm{CD} 4^{+} \mathrm{T}$ cells in vitro, as well as primary $\mathrm{CD}^{+} \mathrm{T}$ cells in vivo upon oral administration of gluten peptide in HLA-DQ2.5 humanized mice, suggesting that the lead antibody 3.C11 has potential to be used for CeD-specific immunotherapy.

\section{Results}

Primary selection of antibodies specific for HLA-DQ2.5 with bound DQ2.5-glia- $\alpha 2$

To generate human antibodies specific for HLA-DQ2.5 in complex with the CeD epitope DQ2.5-glia- $\alpha 2$, a human naïve scFv phage display library (23) was panned against soluble, recombinant pMHC. The method used to select the primary lead was based on our previous selection of a HLA-DQ2.5:DQ2.5-glia- $\alpha$ la-specific antibody (9). After three rounds of selection, we assessed antigen reactivity of the selection output in a polyclonal ELISA and observed increased and preferential binding to the target (fig. S1A). We then reformatted the selection output from the phagemid to a vector for soluble scFv expression and screened 70 single clones for target binding by ELISA (Fig. 1A). A total of 49 single clones bound target preferentially, and sequence analysis identified 14 unique sequences (Fig. 1A, fig. S1B). Five of the clones were enriched in the selection output. Of note, the $\mathrm{V}$ gene segment usage of the single clones was dominated by IGHVI-69, which paired with a diverse set of $I G K V / L V$ segments (fig. S1B, table S1). To characterize the selected scFvs and choose a lead clone, we expressed all unique clones in E. coli and directly compared periplasmic fractions in ELISA for target binding (Fig. 1B). Next, we performed pilot surface plasmon resonance (SPR) measurements using purified scFv (fig. S1C). Based on reactivity profiles and apparent affinities, we chose a lead clone, termed 206. When reformatted to full-length human IgG1 (hIgG1), 206 retained binding to HLA-DQ2.5:DQ2.5-glia- $\alpha 2$, albeit weakly (Fig. 1C, fig. S1D). No binding to the highly similar epitope HLA-DQ2.5:DQ2.5-glia- $\omega 2$ was observed (Fig. 1D). To accurately 
determine the monomeric affinity, a Fab version of 206 was constructed and SPR analysis estimated the monomeric affinity to $\mathrm{K}_{\mathrm{D}} 240 \pm 20 \mathrm{nM}$ with a high off-rate $\left(2.4 \times 10^{-1} \mathrm{~s}^{-1}\right)$ (Fig. 1E).

\section{CDR-targeted secondary library design and selection of high-affinity gluten pMHC-specific antibodies}

Given the low affinity of the 206 clone that was inadequate in e.g. detecting peptide on pulsed model APC (Fig. 6A), we sought to improve the antibody-pMHC interaction by targeted engineering. We generated focused libraries with sequence randomization and increased lengths of either the CDR H1 or H3 loop based on structural models assuming a TCR-like binding mode and the anticipated importance of the CDR H3 loop in target binding. We have previously found high valence (HV) pIX phage display to be very efficient at isolating antibody clones with high affinity and stability (23). Thus, the libraries were prepared accordingly and selected using a stringent strategy aimed at parallel identification of specific binders with high affinity and high thermostability in two separate arms (Fig. 2A). After an initial low-stringency round (R1), the libraries were split into a competition branch (CDR $\mathrm{H} 1$ and $\mathrm{H} 3$ selected separately, libraries denoted $\mathrm{H}^{\mathrm{C}}$ and $\left.\mathrm{H}^{\mathrm{C}}\right)$ and a thermostability branch $(\mathrm{CDR}$ $\mathrm{H} 1$ and $\mathrm{H} 3$ pooled for selection, library denoted " $\mathrm{H} 1 / \mathrm{H}^{\mathrm{T}}$ ") for a highly stringent $\mathrm{R} 2$ with low target concentration followed by a non-stringent R3 loosely based on the hammer-hug selection protocol (24). In R2 of the competition branch, scFvs were displayed at low valence (LV). In the thermal branch, scFvs were displayed at $\mathrm{HV}$ and subjected to a heat challenge at temperatures that induced unfolding of the parent clone (fig. S2A). This was done prior to selection to aggregate and remove unstable library members $(6,25)$. In R3, we aimed at recovering and amplifying selected binders and therefore increased antigen concentration. For the thermal branch, we included a second heat challenge and displayed scFvs at LV to favor clones with high monomeric affinities. The stringent competition in $\mathrm{R} 2$ of the competition branch resulted in close to no selection output in the $\mathrm{CDR} \mathrm{H} 3^{\mathrm{C}}$ library and it was therefore discontinued. To determine antigen reactivity of the output, we performed a polyclonal phage ELISA (fig. S2B). Indeed, the libraries showed signs of enrichment of binders, and we continued to screen single clones from the R3 output as soluble scFv (Fig. 2B) and as scFv displayed on phage (Fig. 2C) by ELISA. Clones with preferential binding to the target were present in both selection branches, and sequence analysis revealed that 
66 out of 73 were unique DNA sequences, and 64 were unique at the amino acid level (fig. S2C). Interestingly, all positive clones came from the CDR H1 library only and most of the unique DNA sequences (56/66) were derived from the library with a loop length increased by 2 residues, with the remaining clones $(10 / 66)$ stemming from the pool with a length increase of 3 residues.

Based on target binding in screening and enrichment of sequence features, we chose 6 clones for large-scale Fab expression in HEK293E cells. These were analyzed regarding their peptide-specificity in ELISA and all were found to bind their HLA-DQ2.5:DQ2.5-glia- $\alpha 2$ target specifically (Fig. 2D, fig. S2D). The Fabs did neither crossreact to the homologous HLA-DQ2.5:DQ2.5-glia- $\omega 2$ complex, which differs at three peptide positions only (p5, p7, and p9), nor with HLA-DQ2.5 with any of the DQ2.5-glia- 1 1, DQ2.5-glia- $\alpha 1$ la or CLIP2 peptides. Thus, the chosen candidates all bound specifically to their target, despite the relatively broad selection of CDR H1 phenotypes (Fig. 2E).

\section{Biophysical characterization of affinity matured pMHC-specific antibodies}

We then performed binding analysis by SPR and ranked the 6 antibodies based on their off-rates (Fig. 2E, Fig. 3A and table S2). Strongly reduced off-rates were observed for all clones tested with clone 3.C11 exhibiting the lowest off-rate. In concordance with the improved (lower) off-rates, 3.C11 had a strong improvement in affinity with a $\mathrm{K}_{\mathrm{D}} 88 \pm 8 \mathrm{pM}$ (Fig. 3B and table S2). This is a 2,700-fold improvement compared to the parent clone. 3.C11 was then expressed as full-length hIgG1 and tested for specific binding in ELISA (Fig. 3C). In agreement with previous results, 3.C11 bound exclusively to HLA-DQ2.5:DQ2.5-glia- $\alpha 2$. Thus, the high affinity antibodies maintained the high specificity of the mother clone.

We next assessed the thermostability of all Fab fragments by determining their melting temperatures using nanoDSF (Fig. 3D). The high-affinity variants surprisingly had slightly lower melting temperatures than their mother clone. The lead clone 3.C11, had the highest thermostabilities out of the engineered clones. Due to its favorable biophysical properties, we selected 3.C11 as a lead candidate for further characterization. 


\section{Structural basis for epitope specificity of $3 . C 11$}

To understand the molecular basis for the specificity and affinity of 3.C11, we crystallized the complex of the 3.C11 Fab fragment and HLA-DQ2.5:DQ2.5-glia- $\alpha 2$ and solved its structure to $2.4 \AA$ resolution (table S3). The structure revealed that the 3.C11 Fab bound HLA-DQ2.5:DQ2.5-glia- $\alpha 2$ with a "TCR-like" docking mode (26) (Fig. 4A and B), which was surprisingly similar to that observed for the prototypic HLA-DQ2.5:DQ2.5-glia- $\alpha 2-$ specific TRAV26-1/TRBV7-2+ TCRs D2, S16 and JR5.1 (27). To characterize the TCR-like features of 3.C11, we compared the structure of the 3.C11 ternary complex with that of the S16 TCR (Fig. 4C and D). The 3.C11 Fab engaged the peptide with all CDR loops (Fig. 4A) with an angle of $57^{\circ}$ between the VL and VH center of mass positions and the axis of the peptide (Fig. 4B). Thus, the VL and VH domains of 3.C11 (Fig. 4B) occupied the place of the canonical TCR V $\alpha$ and V $\beta$ domain binding sites, respectively (Fig. 4D). The overall positioning of 3.C11 on HLA-DQ2.5:DQ2.5-glia- $\alpha 2$ was similar to the TCR in the S16 ternary complex, albeit with the 3.C11 VL and VH center of mass positions offset towards the HLA-DQ2.5 $\alpha$-chain helix by $3.7 \AA$ and $6.1 \AA$ compared to the $\mathrm{S} 16 \mathrm{~V} \alpha$ and $\mathrm{V} \beta$ center of mass positions, respectively (Fig. 4B and D). The layout of the CDR loops relative to the pMHC and the footprint of 3.C11 (Fig. 4B) also broadly resembled that of the S16 TCR (Fig. 4D), such that 3.C11 and S16 shared a large number of pMHC contact residues.

The total buried surface area (BSA) of 3.C11 and HLA-DQ2.5:DQ2.5-glia- $\alpha 2$ was $2385 \AA^{2}$, which is moderately larger than that of the prototypic TCRs S16 $\left(2130 \AA^{2}\right)$, D2 $\left(2145 \AA^{2}\right)$ and JR5.1 (1765 $\left.\AA^{2}\right)$. The increase was mainly attributable to additional pMHC contacts made by the 3.C11 CDR H1 and CDR H2. With a BSA contribution of 76.2\%, the 3.C11 H-chain dominated the pMHC interface, with relatively even contributions made by CDR H3 (27.5\%), CDR H2 (22.7\%) and CDR H1 (22.4\%). The smaller interface of the L-chain (23.8\%) featured CDR L1 (11.2\%) as the largest contributor (Fig. 4B and 4D). The dominant role of the H-chain in the 3.C11 pMHC interface broadly reflected the relative contributions of the $\beta$-chains observed for TCRs S16 (59.7\%, Fig. 4D), D2 (62.8\%) and JR5.1 (73.6\%). Accordingly, the moderately larger BSA of 3.C11 compared to the TCRs contributes to the vastly higher affinity of 3.C11. The 3.C11 Fab-pMHC interface comprises 5 H-bonds and 3 salt bridges, which is 
numerically comparable to the $12 \mathrm{H}$-bonds present in the pMHC interface of S16 TCR. To further investigate the basis for the vastly higher affinity of 3.C11 compared to the S16 TCR, we calculated the geometric surface complementarity of the interfaces using SC (28), which resulted in nearly identical shape complementarity (SC) values for 3.C11 $(\mathrm{SC}=0.691)$ and $\mathrm{S} 16(\mathrm{SC}=0.684)$. To investigate the charge complementarity of the complexes, we calculated the electrostatic surface potentials of the 3.C11 (fig. S3A) and S16 (fig. S3B) complexes using the Adaptive Poisson-Boltzmann Solver (APBS) (29). The results revealed an overall similar polarity of the surface potential on 3.C11 and S16. 3.C11 showed an additional positively charged patch in the area of CDR H1 which was opposed by an overall weakly charged area on the pMHC (fig. S3A) and is therefore unlikely to drive the vast difference in affinities.

In accordance with the positional shift towards the HLA-DQ2.5 $\alpha$-chain, compared to the S16 TCR, 3.C11 formed an extensive interface with the HLA-DQ2.5 $\alpha$-chain (48.3\%) and comparatively smaller interfaces with the HLADQ2.5 $\beta$-chain (35.3\%) and the peptide (16.5\%) (Fig. 4B and D). The CDR H2 and CDR H3 loops made the largest contribution to the interface with the HLA-DQ2.5 $\alpha$-chain. Here, the CDR H3 loop contacted the inner side of the peptide binding cleft, whereas the CDR H2 cupped the top and outer side of the HLA-DQ2.5 $\alpha$-chain helix (Fig. 5A). Notably, the hydrophobic core of the CDR H2 - HLA-DQ2.5 $\alpha$-chain interface was comprised of germline residues unique to IGHV1-69 (Ile57, Ile59, Phe62), which suggests that the preferential IGHVI-69 selection as observed is in part driven by these interactions. Moreover, key elements of the 3.C11 Fab-pMHC interface were surprisingly similar to features observed for the S16 TCR - HLA-DQ2.5:DQ2.5-glia- $\alpha 2$ interface. Namely, the peptide residues directly contacted by $3 . \mathrm{C} 11$ (p2, p5, p6, p7, p8, p9 and p11) (Fig. 5B) included all peptide residues contacted by S16 (p2, p5, p6, p7 and p8) (Fig. 5C), and the interaction pattern of 3.C11 with the peptide (CDR L1 $\rightarrow$ p2; CDR H3 $\rightarrow$ p5, p6, p7; CDR H1 $\rightarrow$ p8, p9, p11) closely resembled that observed in the S16 complex (CDR $\alpha 1 \&$ CDR $\alpha 3 \rightarrow$ p2; CDR $\beta 3 \rightarrow$ p5, p6, p7; CDR $\beta 1 \rightarrow$ p8). Both the CDR H3 loop of 3.C11 (Fig. 4B), and the CDR $\beta 3$ loop of S16 (Fig. 4D) formed brace-like structure across the central portion of the peptide and bridge across the peptide binding cleft (Fig. 5A). 
The prototypic TRAV26-1/TRBV7-2 TCRs, such as S16, are preferentially selected by HLA-DQ2.5:DQ2.5-glia- $\alpha 2$ and generally contain a non-germline encoded Arg residue in CDR $\beta 3$ (Fig. 5C), which is critical for pMHC recognition $(27,30)$. In 3.C11, Gln 109 at the tip of the CDR H3 loop took up the position of this Arg residue (Fig. $5 \mathrm{~A})$.

To determine the impact of each peptide amino acid position on 3.C11 binding, we performed an alanine scan of the DQ2.5-glia- $\alpha 2$ peptide. Compared to TCRs 364 and S16 (fig. S4A and B), 3.C11 binding was affected by mutagenesis over the entire peptide length, with a $>50 \%$ reduction in binding observed for mutation of $\mathrm{p} 4-\mathrm{Glu}, \mathrm{p} 5-$ Leu and p10-Pro (fig. S4C), consistent with the 3.C11 footprint covering peptide residues p2 to p11, while the S16 footprint covered peptide residues p2 to $\mathrm{p} 8$ and was highly sensitive to substitution of residues p3 to p8 (fig. S4B).

\section{Structural basis for affinity enhancement of $3 . C 11$}

The differences between the parental 206 and the affinity matured leads reside within the CDR H1 loop, which, in the case of 3.C11, replaced a four-residue segment (GGTFSSYA) with a new six-residue segment (GGTVRSRVHA). The CDR H1 loop of 3.C11 formed a short helical segment that sat atop of p8-Pro and interacted with the backbone of the C-terminal peptide residues p9 and p10, as well as with both the HLA-DQ2.5 $\alpha$ - and $\beta$-chains (Fig. 5A). The interface between CDR H1 and HLA-DQ2.5:DQ2.5-glia- $\alpha 2$ was mediated by interdigitating interactions of the helix backbone, the sidechains of Val30 and Val36 at either end of the CDR H1 helical turn, and Arg31, which further formed a salt bridge with HLA-DQ2.5- $\alpha$ Asp66, and a H-bond with Q64 (Fig. 5A). To better understand the basis for the affinity enhancement of 3.C11 over the parental clone 206 containing the canonical IGHV1-69 CDR H1, we compared the structures of 4 published IGHV1-69 Fabs with canonical IGHV1-69 CDR H1 loos to 3.C11 (Fig. 5A, box inset). Alignment of IGHV1-69 revealed a consensus positioning at the N-terminal end of the CDR H1 loops, which suggested that the shorter CDR H1 loop of 206 was likely to interact with the HLA-DQ2.5 $\alpha$-chain and p8-Pro of the peptide, but was clearly too short to reach the HLA-DQ2.5 $\beta$-chain. Accordingly, the affinity maturation of the CDR H1 loop in 3.C11 created an extension that allowed a short helical segment to form multi-angle peptide contacts and effectively bridged the peptide binding cleft and added a salt bridge and a H-bond with the HLA-DQ2.5 $\beta$-chain. Notably, all of the affinity enhanced 
clones featured an extended CDR H1 loop (Fig. 2E), suggesting that the affinity gain in each clone is based on the introduction of additional BSA and discrete binding interactions with both the peptide and the HLA-DQ2.5 $\beta$ chain.

\section{Detection of gluten-peptide presentation on cell lines and human small intestinal biopsy material}

Having demonstrated specificity and improved affinity of the antibodies to soluble, recombinant pMHC molecules, we tested whether the antibodies would bind pMHC complexes on the surface of cells. We loaded HLA-DQ2.5 Raji B lymphoma cells (31) with soluble gluten peptides. To exclude species-dependent cross-reactivity, the antibodies were reformatted and expressed as mIgG2b (fig. S5A). Whereas the mother clone 206 failed to show detectable binding to peptide-loaded Raji cells, the high-affinity variant 3.C11 exhibited specific binding to cells loaded with DQ2.5-glia- $\alpha 2$ or 33mer peptides (Fig. 6A). Of note, the 33mer contains 3 overlapping copies of the DQ2.5-glia- $\alpha 2$ epitope and is thought to be presented on APCs in the celiac lesion (32). Flow cytometric analysis using A20 B cells engineered to express HLA-DQ2.5 with covalently linked DQ2.5-glia- $\alpha 2$ peptide, improved baseline separation compared to staining of peptide-loaded Raji cells and 3.C11 binding was comparable to a panHLA-DQ2 antibody, indicating that loading only results in a fraction of MHC molecules being occupied with specific peptide (Fig. 6A and fig. S5B)

To further assess the HLA restriction of the antibodies, human EBV transduced B-cell lines of different HLA-DQ allotypes were loaded with gluten peptides and immediately stained (Fig. 6B, fig. S5C). HLA-DQ2.2 binds DQ2.5glia- $\alpha 2$ less stably than HLA-DQ2.5, and HLA-DQ8 is not expected to bind them at all (33). The flow cytometry experiments confirmed that 3.C11 is pMHC-specific, binding to peptide presented on either HLA-DQ2.5 or the closely related HLA-DQ2.2.

We recently showed that a HLA-DQ2.5:DQ2.5-glia- $\alpha 1$ a-specific antibody termed 107 specifically stained B cells and PCs in single-cell suspensions made from inflamed intestinal biopsies derived from HLA-DQ2.5 ${ }^{+} \mathrm{CeD}$ patients who consumed gluten (9). Here, we again generated fresh single-cell suspensions from such HLA-DQ2.5 CeD patients that were on a gluten containing diet (untreated, UCeD), or control subjects with normal gut 
histology. We then stained with the mIgG2b version of 107 or 3.C11, as well as antibodies with different APC surface marker specificities (Fig. 6C-F, fig. S6A-D). Indeed, we confirmed the previous observation using the more sensitive high-affinity antibody. The two antibodies stained PCs from UCeD patients with roughly the same staining pattern and level (Fig. 6C, fig. S6C and D). The results of the staining of PCs from five control subjects suggested that there was little background staining with both antibodies (Fig. 6D). Two out of eight patient samples were seemingly negative for the targeted pMHC using both antibodies. We further extended the analysis to pMHC expressed on DCs and Mfs (Fig. 6E and F). The pMHC-specific antibodies did not stain cells in control subjects, but they appeared to detect low levels of peptide presentation in HLA-DQ2.5 $5^{+}$UCeD patients. Of note, the total number of DCs/Mfs was low in the biopsy material.

\section{High-affinity antibodies are potent inhibitors of T-cell activation in vitro}

Having confirmed that cell-surface pMHC was specifically detected both on in vitro peptide-loaded cells and on patient-derived APCs loaded in vivo, we wondered if we could block the interaction between T cells and APCs using the high-affinity antibody. The DQ2.5-glia- $\alpha 2$ is the most extensively characterized gluten T-cell epitope to which all HLA-DQ2.5 $5^{+}$eD patients appear to mount a T-cell response $(22,34)$.

To determine the inhibitory capacity of 3.C11, human SKW3 T cells devoid of endogenous TCR were engineered to express TCRs that were cloned from CeD patients, and that were specific for HLA-DQ2.5 with DQ2.5-gliaala (TCR 380 (21)) or DQ2.5-glia- 22 (TCR S16 (27) and TCR 364 (30)). We loaded Raji B cells with titrated amounts of stimulatory DQ2.5-glia- $\alpha 2$ 12-mer gluten peptide and co-cultured them with the SKW3 T cells. Tcell activation was measured by determining upregulation of CD69 expression on the SKW3 T cells using flow cytometry (fig. S7A and B). A peptide concentration inducing 60\% T-cell activation was chosen for subsequent experiments, where the peptide-loaded Raji B cells were incubated with 3.C11 or control antibodies upon addition of SKW3 T cells (Fig. 7A). Indeed, 3.C11 specifically and completely inhibited T-cell activation of the SKW3 364 T cells specific for HLA-DQ2.5:DQ2.5-glia- $\alpha 2$, while the HLA-DQ2.5:DQ2.5-glia- $\alpha 1$-a-specific SKW3 380 $\mathrm{T}$ cells were unaffected. The effect was HLA-DQ-specific as inhibition was observed using a pan HLA-DQ antibody (SPV-L3), whereas no effect was seen with a pan HLA-DR antibody (L243). This strong inhibitory 
capacity was not seen with the low affinity 206 counterpart (Fig. 7A). To quantify the inhibitory efficacy, we did a titration of 3.C11 in the same T-cell activation assay using the 33mer as stimulating antigen (fig. S7C and D). In line with the very high affinity of the antibody, the IC50 indexes were found to be in the low picomolar range. Notably, the inhibition was markedly more sensitive on the effector property of the T cells based on IL-2 cytokine production than the corresponding effect on the early activation marker CD69 (IC50s of $39 \mathrm{pM}$ vs $360 \mathrm{pM}$ for SKW3 364 T cells, and 36 pM vs 130 pM for SKW3 S16 T cells, respectively). We next assessed the specificity of this inhibitory capacity by loading Raji B cells separately with DQ2.5-glia- $\alpha 1$ a or DQ2.5-glia- $\alpha 2$ or a mix of both peptides. We further included the 33mer gliadin peptide. The peptide loaded Raji B cells were co-cultured with a blend of SKW3 380 T cells and CFSE labelled SKW3 364 T cells (Fig. 7B). As seen, 3.C11 specifically inhibited activation of the SKW3 364 T cells but did not affect epitope-specific activation of the SKW3 380 T cells, not even when the epitopes are simultaneously presented on the same HLA allotype by the same cell population. To test if this effect also held true for an unrelated T-cell response restricted to a different HLA allotype, we repeated the assay using HLA-DQ2.5 ${ }^{+}$and HLA-DP4 ${ }^{+} \mathrm{K} 562$ cells, loaded with antigenic peptides, in combination with SKW3 364 T cells or the MAGE-A3-specific SKW3 R12C9 T cells restricted to HLA-DP4 (Fig. 7C). As in the previous assay, 3.C11 fully blocked SKW3 $364 \mathrm{~T}$ cells whereas there was no effect on the SKW3 R12C9 T cells.

Finally, we tested the effect of 3.C11 on proliferation of primary T-cell clones (TCCs) derived from CeD patients. We co-cultured the HLA-DQ2.5:DQ2.5-glia- $\alpha 2$-specific TCC820.250 with Raji B cells loaded with 12mer DQ2.5-glia- $\alpha 2$ or the 33 mer gliadin peptide and measured proliferation as incorporation of 3H-thymidine (Fig. 7D, fig. S8A). In line with the inhibition of the reconstructed SKW3 T cells, we here observed a complete inhibition of T-cell proliferation for both the minimal epitope and the highly stimulatory 33mer peptide. We then performed a similar experiment using four different HLA-DQ2.5:DQ2.5-glia- $\alpha 2$-specific TCCs and added titrated amounts of antibodies to determine the inhibitory effect of mAb 3.C11 on T-cell proliferation as well as secretion of IFN- $\gamma$ (Fig. 7E, fig. S8A, B and C). Antibody 3.C11 inhibited T-cell proliferation (Fig. 7E and fig. S8B) and IFN- $\gamma$ secretion (fig. S8C) in a concentration-dependent manner, while control antibodies had minimal to no effect. 
mAb 3.C11 blocks gliadin-dependent primary $C D 4^{+}$T-cell proliferation in HLA-DQ2.5 humanized mice

Although the in vitro inhibitory capacity of mAb 3.C11 even on antigen experienced human primary TCCs was highly encouraging, it is difficult to translate the impact to the more complex environment of the human gut. Currently, there is no HLA-DQ2.5 humanized preclinical model that recapitulates the gluten-dependent immunemediated enteropathy of $\mathrm{CeD}$. As an approximation, we therefore turned to a mouse model relying on adoptive transfer of naive $\mathrm{CD}^{+} \mathrm{T}$ cells isolated from HLA-DQ2.5 knock-in (KI)/TCR-glia- $\alpha 2$ transgenic (tg) mice (35) into HLA-DQ2.5 KI recipient mice (36). This allowed us to study antigen-specific T-cell proliferation in the gutassociated lymphoid tissue and draining mesenteric lymph nodes upon oral administration of the antigen (Fig. 8A). The day following adoptive cell transfer, $200 \mu \mathrm{g}$ of antibodies (or PBS) were given by intraperitoneal (i.p.) injection followed by intragastric administration of $100 \mu \mathrm{g}$ deamidated gluten 33mer peptide. A second dose of antibodies (or PBS) was given the next day. Mice were euthanized $48 \mathrm{~h}$ after peptide administration and T-cell proliferation in the gut-draining mesenteric lymph nodes (MLN), gut Peyer's patches (PP), the spleen and control lymph nodes (non-draining inguinal lymph nodes (ILN) was determined. Whereas about $60 \%$ of recovered T cells proliferated in the MLN and PPs of mice receiving i.p. PBS or the isotype control antibody, administration of 3.C11 efficiently blocked T-cell proliferation in these lymphoid tissues (Fig. 8B and C). In contrast to the complete blocking effect of 3.C11, the pan-HLA-DQ mAb SPV-L3 was less efficient, inhibiting proliferation to an intermediate extent of $34 \%$ and $23 \%$ in the MLN and PPs, respectively. Oral gavage of gluten peptide resulted in a weak peripheral T-cell proliferation in three of the ten mice (ILN) possibly due to systemic distribution of the peptide antigen (Fig. 8C). Notably, no such T cell proliferation was seen in the ILN of the mice receiving 3.C11 or the pan-DQ antibody SPV-L3. 


\section{Discussion}

We here report the generation of a human high-affinity TCR-like antibody termed 3.C11 specific for the pMHC complex HLA-DQ2.5:DQ2.5-glia- $\alpha 2$ by use of phage display. This engineered antibody allowed us to extend the results from a previous study that focused on one epitope only (9), and enabled detection of cells with low levels of peptide presentation. Importantly, 3.C11 potently inhibited T-cell activation in vitro and in vivo and may thus have therapeutic potential.

The primary lead 206, as well as our previously reported antibody 107 , which is specific for the HLADQ2.5:DQ2.5-glia- $\alpha$ la complex (9), were selected from a human naïve scFv library that contains light and heavy chain gene segments from diverse endogenous repertoires $(23,37)$. While the three HLA-DQ2.5:DQ2.5-glia- $\alpha 1 \mathrm{a}$ lead candidates used the germline segments IGHV6-1 and IGKVI-9 (table S1), the eight lead candidates against the HLA-DQ2.5:DQ2.5-glia- $\alpha 2$ complex all used the IGHV1-69 segment and diverse $I G K V$ segments. Thus, our data suggest a preference primarily for VH germlines to acquire specificity, and the fact that we employed an antibody library based on a diverse, endogenously derived gene repertoire may have been crucial for the success of the primary selections.

In a previous study, we displayed scFv at $\mathrm{HV}$ on pIX and observed efficient enrichment of full-length functional scFvs during selection. We retrieved clones with higher affinity and thermostability in direct comparison to both LV and HV display on pIII (23), suggesting that HV display on pIX could be particularly valuable for affinity engineering. Thus, we chose pIX as a display scaffold for the second-generation libraries to select for high affinity variants, which indeed turned out highly successful.

The crystal structure of Fab 3.C11 bound to HLA-DQ2.5:DQ2.5-glia- $\alpha 2$ showed that the Fab utilized a docking mode strikingly similar to that of TCRs, sharing several contact residues with prototypic DQ2.5-glia- $\alpha 2$-specific TRAV26-1/TRBV7-2 TCRs (27). This contrasts the pMHC binding mode of other TCR-like antibodies, which either deviated from the TCR diagonal binding mode or focused on peptide hotspots (38). 3.C11 interact with the pMHC using all six CDR loops. Notably, 7 out of 9 amino acids of the peptide core are contacted, a feature found indicative of high peptide specificity (38). 3.C11 also engages several residues of both the MHC $\alpha$ - and $\beta$-chains. 
In particular, the strong selection of IGHVI-69 in the candidate clones after the primary selection can in part be explained by the hydrophobic CDR H2 of this germline segment forming a strong interface with the MHC $\alpha$-chain. A signature feature of the semi-public TCRs is the presence of a conserved Arg residue in the apex of CDR3 which invariably interacts with p5-Leu, p6-Pro of DQ2.5-glia- $\alpha 2$ and Thr61, Asn62, and Val65 of the HLA-DQ2.5 $\alpha$-chain $(27,30)$. Interestingly, in 3.C11 CDR H3-Gln109 appears to play an equivalent role. The high complexity of the CDR H3 layout and interactions may explain the lack of binders enriched from the CDR H3 library, as CDR $\mathrm{H} 3$ engineering would disrupt the delicate arrangement of interdependent interactions for most library members. In contrast to the CDR H3 library, the selection of the CDR H1 libraries resulted in high-affinity binders. Notably, the libraries were designed to contain only CDR H1 loops elongated by two or three amino acids, which likely contributed to the large BSA contribution made by this loop. In the case of the 3.C11 complex, the CDR H1 loop formed a short $\alpha$-helix that results in a rigid CDR H1 conformation and extended interactions with the peptide Cterminus. This suggests that the substantial increase in binding affinity may in part be driven by stabilizing intraloop interactions in addition to an increased BSA. Affinity enhanced Fabs may therefore in principle be engineered from initial binders via addition and selection of self-stabilizing elements in peripheral CDR loops.

We observed staining of patient biopsies using both 107 and 3.C11, and primarily detected PCs which are characteristically expanded in celiac lesions. We detected only minimal staining of the few $\mathrm{CD} 14^{+}$or $\mathrm{CD} 11 \mathrm{c}^{+} \mathrm{Mfs}$ and DCs using our TCR-like antibodies, despite a high HLA class II expression (9). Mf and DC subsets were previously shown to occur at altered frequencies in the lamina propria of $\mathrm{CeD}$ patients and were therefore suggested to contribute as an important tissue APC in CeD pathogenesis (39-42). Thus, detection of peptidepresenting DCs may e.g. have been affected by migratory behavior to the gut-draining MLN upon antigen encounter (42).

Our previous and current data strongly indicate a peptide-presentation pattern where the B-cell compartment dominates as APCs at least in the inflamed tissue with high disease activity (9). Despite the high affinity of 3.C11, we did however not detect peptide presentation in all patient samples independent of APC type alluding to the complexity of the epitope landscape in this heterogeneous disease. The reason for lack of detection in peptide- 
presentation seen for some patients is unknown. However, detection would require that the patients have maintained a gluten-containing diet until the time of gastroendoscopy. In addition, differences in wheat strains and $\alpha$-gliadin gene content used for food (43), as well as individual variation in ability to proteolytic digest gluten (44) are factors that might underpin the lack of staining in some of the CeD patient samples.

mAb 3.C11 specifically inhibited T-cell activation and proliferation in vitro and in vivo. This clearly demonstrates the benefit of targeting specific epitopes on MHC complexes to avoid a large in vivo antigenic sink effect presumably seen using the pan-HLA-DQ mAb, even in this targeted HLA-DQ2.5 KI mouse expressing MHCII exclusively on APCs. The effect in vivo was observed in mice which represent the critical role of TCR and HLADQ2.5 as seen in $\mathrm{CeD}$, but which is not a complete mouse model of CeD. Among others, the mice do not recapitulate the B-cell centric APC compartment with abundant plasma cells specific for gluten or TG2 as seen in CeD patients, as well as the gut inflammation with complex tissue remodeling as seen in human CeD. $(9,45,46)$. At present, the precise mode of action for the observed blockade of T-cell proliferation has not been clarified, and needs to be addressed further in future studies. Antibodies specific for single epitopes presented on MHC have previously been suggested as potential therapeutics in other autoimmune disease $(3,47,48)$ and cancer $(49,50)$. Antibodies targeting type 1 diabetes (T1D)-associated autoantigens bound to human or murine MHC class II molecules have been engineered and found to exhibit T-cell inhibitory capacity in vitro and in mouse models $(3$, 47). Decreased activation of antigen-specific $\mathrm{T}$ cells in lymph nodes and spleen has been observed in immunized HLA-DR4 transgenic mice treated with an antibody against a glutamic acid decarboxylase 65 peptide in complex with HLA-DR4 (3). Treatment with a different antibody against the B:9-23 insulin peptide bound to the murine MHC variant $\mathrm{IA}^{\mathrm{g} 7}$ delayed disease onset and progression in non-obese diabetic mice, which could be attributed to a decrease in lymphocytes infiltrating the pancreatic islets. This observation was disease-specific, but not restricted to insulin-specific T cells and seen for both $\mathrm{CD}^{+}$and $\mathrm{CD} 8^{+} \mathrm{T}$ cells, as well as B cells (47). Recently, a high-affinity antibody against the $\mathrm{B}: 9-23-\mathrm{IA}^{\mathrm{g} 7}$ complex was isolated and was found more effective in preventing T-cell activation and protecting against T1D compared to the low-affinity antibody. Treatment with the highaffinity antibody against the B:9-23 insulin epitope also had an effect when administered at a disease stage where 
epitope-spreading had already occurred (51). While it is unclear whether targeting the immunodominant DQ2.5glia- $\alpha 2$ epitope alone is sufficient for treatment of CeD, these studies with TCR-like antibodies in T1D are promising as they have shown that a high-affinity antibody inhibiting a single T-cell epitope may be sufficient to induce a more tolerogenic immune response and delay disease onset or progression in a preclinical model of a complex autoimmune disease. Thus, the ability of mAb 3.C11 to efficiently prevent T-cell activation encourages further studies to assess the therapeutic potential in inhibition, cytotoxicity or induction of infectious tolerance for treatment of CeD.

\section{Material and Methods}

\section{Design}

The primary objective of this study was to generate and engineer high-affinity human antibodies with specificity for a $\mathrm{pMHC}$ complex characteristic of $\mathrm{CeD}$ and to use this antibody for detection of peptide-presentation in patient samples. A secondary objective was to determine the therapeutic potential of the lead antibody by performing proof-of-concept experiments. We used a naïve fully human antibody phage library for a primary selection to identify binding clones, followed by a secondary CDR-targeted library to obtain antibodies with high specificity and affinity. The samples size for single-clone screening after phage selections was determined based on previous experience to achieve a sufficient number of antigen-reactive clones. Single clones were chosen randomly and screening experiments were performed once. Binding studies (ELISA, SPR) and cellular studies (flow cytometry, T-cell assays) were performed two or three independent times (unless stated otherwise) with duplicate or triplicate samples where appropriate and as specified in the figure legends. Collection of human duodenal biopsy material from CeD patients and small intestinal resections (distal duodenum/proximal jejunum) from patients undergoing Whipple procedure was approved by the Regional Ethics Committee of South-Eastern (REK Sør-Øst approval ID 6544). All subjects gave informed written consent to donate biological material to a REK Sør-Øst approved biobank (ID 20521). Subjects with suspected CeD were referred for biopsy sampling at Oslo University Hospital or Akershus University Hospital. Disease status (CeD diagnosis or not) was unknown to the investigator at the 
time of performing and analyzing the experiment. Normal histology of the duodenal mucosa was confirmed in the small-intestinal resections, thus serving as a non-inflammatory control sample. For in vivo experiments, animals were randomly assigned into treatment groups and the sample size was determined based on previous experience and is specified in the figure legend. Due to a technical issue, data from the spleen of one mouse was excluded post analysis. The in vivo experiments were approved by the Norwegian Food Safely Authority (Mattilsynet). All results shown are either representative of or mean of independent experiments.

\section{Antibody engineering, characterization and functional studies}

Methods for antibody engineering are described in detail in the SI Materials and Methods. Briefly, first-generation HLA-DQ2.5:DQ2.5-glia- $\alpha 2$-specific antibodies were isolated from a human naïve scFv phage library (37) selected on recombinant pMHC essentially as described before $(9,23)$.

Targeted phage libraries were constructed using degenerate oligonucleotides and $\mathrm{scFv}$ were displayed on phage coat protein pIX (52) and selected for high affinity and stability using a protocol based on (24). Candidate clones were assessed in nanoDSF, ELISA, SPR, and flow cytometry experiments. The Fab:pMHC complex was crystallized using the sitting drop vapor diffusion method and solved to a resolution of $2.4 \AA$ and is deposited with the Protein Data Bank under PDB ID 6XPX. Inhibition of T-cell activation and proliferation was assayed by reading out CD69 expression of retrovirally transduced gluten-specific T-cells in flow cytometry and in thymidine incorporation assays using primary human TCCs, respectively. For in vivo T-cell proliferation experiments, $\mathrm{CD}^{+}$ T cells were transferred from HLA-DQ2.5 KI/TCR-glia- $\alpha 2$ tg mice into HLA-DQ2.5 KI recipient mice, followed by intraperitoneal administration of antibodies and oral administration of deamidated gluten 33mer peptide and flow cytometric analysis of secondary lymphoid organs.

\section{Statistical Analysis}

Statistical analysis was performed using GraphPad Prism 8.0.1 or 9.1.0.221. Statistical tests and $P$ values are described in figure legends. A $P$ value $<0.05$ was considered significant. Data are presented as means $\pm \mathrm{SD}$ or as 
minimum to maximum boxes with mean as described in the figure legends. SPR binding data values were buffer subtracted and reference-cell subtracted using the Biacore T200 Evaluation Software v1.0. For visual comparison of off-rates in SPR, the individual cures were normalized to a maximum binding of $100 \%$ using Biacore T200 Evaluation Software v1.0.

\section{Supplementary Materials}

Materials and methods

Fig. S1. Primary selection against HLA-DQ2.5:DQ2.5-glia-a2.

Fig. S2. Selection for high affinity antibodies.

Fig. S3. Electrostatic surface potential of Fab 3.C11 and TCR S16 with pMHC.

Fig. S4. DQ2.5-glia- $\alpha 2$ peptide reactivity pattern of HLA-DQ2.5:DQ2.5-glia- $\alpha 2$-specific T cells and mAb 3.C11.

Fig. S5. Staining for HLA-DQ2 expression and detection of cell surface pMHC using antibody 3.C11.

Fig. S6. The pMHC-specific antibodies detect gluten peptide presentation on PC subsets in CeD small intestinal biopsies.

Fig. S7. Activation of gluten-specific SKW3 T cells.

Fig. S8. Inhibition of gluten-specific TCCs.

Table S1. Gene segment usage among the HLA-DQ2.5:DQ2.5-glia- $\alpha 1$ a-specific and the HLA-DQ2.5:DQ2.5glia- $\alpha 2$-specific clones ( 8 lead candidates from the first generation).

Table S2. Kinetics and affinity of the HLA-DQ2.5:DQ2.5-glia- $\alpha 2$-specific antibodies.

Table S3. Data collection and refinement statistics.

Table S4. Raw data file (Excel spreadsheet).

Acknowledgements: We would like to thank Sathiaruby Sivaganesh, Marie K. Johannesen, Bjørg Simonsen, Liv Kleppa and Gøril Berntzen for technical assistance, as well as Ute Krengel for helpful discussions. We thank The Flow Cytometry Core facility at Oslo University Hospital for assistance with cell sorting, the Department of 
Immunology at Oslo University Hospital for HLA-typing and the staff of the Department of Comparative Medicine, Oslo University Hospital, for animal husbandry. The crystallographic research was undertaken at the Australian Synchrotron, part of ANSTO. We thank the staff at the Australian Synchrotron for assistance with data collection, the staff at the Monash Macromolecular crystallization facility. Parts of figures were created with BioRender.com. Funding: This work received funding from the South-Eastern Norway Regional Health Authority (grants 2016039 and 2018067) and the Research Council of Norway through its Centers of Excellence funding scheme, project number 179573/V40 and Stiftelsen Kristian Gerhard Jebsen (project SKGJ-MED-017). JRJ and JJG were supported by the U.S. National Institutes of Health grants R01-GM078221 and F31-GM078221. The computations were performed on resources provided by the Maryland Advanced Research Computing Center (MARCC) and UNINETT Sigma2 - the National Infrastructure for High Performance Computing and Data Storage in Norway. JR is supported by an ARC Laureate Fellowship and ARC Centre of Excellence in Advanced Molecular Imaging. Author Contributions: RF, LSH, JP, MFdP, SK, GB, AED, JRJ, KSG, TF, ESV, and CL designed and performed research and analyzed data. KEAL and JJ performed endoscopic examination and provided biopsies. SY provided intestinal resections. JJG, JR, LMS, IS, and GÅL designed research, analyzed data and supervised the study. RF, LSH, JP, IS, and GÅL wrote the manuscript. All authors critically reviewed the manuscript. Competing interests: RF, LSH, LMS, IS, and GÅL are joint authors on a patent application describing the pMHC-specific antibodies. GÅL is affiliated with Nextera AS. GÅL and IS hold shares in Nextera AS. LMS, privately or via his employer, has been a consultant during the two last years for Amagma Therapeutics, Intrexon Actobiotics, Bioniz Therapeutics, Chugai Pharmaceutical, Merck, Topas Therapeutics and GSK. KEAL privately or via his employer, has been a consultant during the two last years for Amyra GMBH Intrexon Actobiotics, Bioniz Therapeutics, Chugai Pharmaceutical and Takeda. All other authors disclose no conflict of interest. Data and materials availability: The crystal structure of Fab 3.C11 in complex with HLADQ2.5:DQ2.5-glia- $\alpha 2$ is deposited under PDB ID 6XPX (released upon publication of the manuscript). 


\section{References}

1. M. Krogsgaard, K. W. Wucherpfennig, B. Cannella, B. E. Hansen, a Svejgaard, J. Pyrdol, H. Ditzel, C. Raine, J. Engberg, L. Fugger, Visualization of myelin basic protein (MBP) T cell epitopes in multiple sclerosis lesions using a monoclonal antibody specific for the human histocompatibility leukocyte antigen (HLA)-DR2-MBP 8599 complex., J. Exp. Med. 191, 1395-1412 (2000).

2. J. A. Weidanz, P. Piazza, H. Hickman-Miller, D. Woodburn, T. Nguyen, A. Wahl, F. Neethling, M. ChirivaInternati, C. R. Rinaldo, W. H. Hildebrand, Development and implementation of a direct detection, quantitation and validation system for class I MHC self-peptide epitopes, J. Immunol. Methods 318, 47-58 (2007).

3. R. Dahan, J. a Gebe, A. Preisinger, E. a James, M. Tendler, G. T. Nepom, Y. Reiter, Antigen-specific immunomodulation for type 1 diabetes by novel recombinant antibodies directed against diabetes-associates autoreactive T cell epitope., J. Autoimmun. 47, 83-93 (2013).

4. L. S. Høydahl, R. Frick, I. Sandlie, G. A. Løset, Targeting the MHC Ligandome by Use of TCR-Like Antibodies, Antibodies 8, 32 (2019).

5. G. Å. Løset, G. Berntzen, T. Frigstad, S. Pollmann, K. S. Gunnarsen, I. Sandlie, Phage Display Engineered T Cell Receptors as Tools for the Study of Tumor Peptide-MHC Interactions, Front. Oncol. 4, 1-7 (2015).

6. K. S. Gunnarsen, S. G. Kristinsson, S. Justesen, T. Frigstad, S. Buus, B. Bogen, I. Sandlie, G. Å. Løset, Chaperone-assisted thermostability engineering of a soluble T cell receptor using phage display., Sci. Rep. 3, 1162 (2013).

7. Y. Li, R. Moysey, P. E. Molloy, A.-L. Vuidepot, T. Mahon, E. Baston, S. Dunn, N. Liddy, J. Jacob, B. K. Jakobsen, J. M. Boulter, Directed evolution of human T-cell receptors with picomolar affinities by phage display, Nat. Biotechnol. 23, 349-354 (2005).

8. F. D. Batista, M. S. Neuberger, Affinity Dependence of the B Cell Response to Antigen: A Threshold, a Ceiling, and the Importance of Off-Rate, 8, 751-759 (1998).

9. L. S. Høydahl, L. Richter, R. Frick, O. Snir, K. S. Gunnarsen, O. J. B. B. Landsverk, R. Iversen, J. R. Jeliazkov, J. J. Gray, E. Bergseng, S. Foss, S.-W. W. Qiao, K. E. A. A. Lundin, J. Jahnsen, F. L. Jahnsen, I. Sandlie, L. M. Sollid, G. Å. Løset, Plasma Cells Are the Most Abundant Gluten Peptide MHC-expressing Cells in Inflamed 
Intestinal Tissues From Patients With Celiac Disease, Gastroenterology 156, 1428-1439.e10 (2019).

10. K. Lindfors, C. Ciacci, K. Kurppa, K. E. A. Lundin, G. K. Makharia, M. L. Mearin, J. A. Murray, E. F. Verdu, K. Kaukinen, Coeliac disease, Nat. Rev. Dis. Prim. 5, 3 (2019).

11. V. Abadie, L. M. Sollid, L. B. Barreiro, B. Jabri, Integration of genetic and immunological insights into a model of celiac disease pathogenesis., Annu. Rev. Immunol. 29, 493-525 (2011).

12. O. Molberg, S. N. Mcadam, R. Körner, H. Quarsten, C. Kristiansen, L. Madsen, L. Fugger, H. Scott, O. Norén, P. Roepstorff, K. E. Lundin, H. Sjöström, L. M. Sollid, Tissue transglutaminase selectively modifies gliadin peptides that are recognized by gut-derived T cells in celiac disease., Nat. Med. 4, 713-7 (1998).

13. Ø. Molberg, S. McAdam, K. E. A. Lundin, C. Kristiansen, H. Arentz-Hansen, K. Kett, L. M. Sollid, T cells from celiac disease lesions recognize gliadin epitopes deamidated in situ by endogenous tissue transglutaminase, Eur. J. Immunol. 31, 1317-1323 (2001).

14. B. Jabri, L. M. Sollid, Tissue-mediated control of immunopathology in coeliac disease., Nat. Rev. Immunol. 9, 858-870 (2009).

15. L. M. Sollid, S. W. Qiao, R. P. Anderson, C. Gianfrani, F. Koning, Nomenclature and listing of celiac disease relevant gluten T-cell epitopes restricted by HLA-DQ molecules, Immunogenetics 64, 455-460 (2012).

16. J. a Tye-Din, J. a Stewart, J. a Dromey, T. Beissbarth, D. a van Heel, A. Tatham, K. Henderson, S. I. Mannering, C. Gianfrani, D. P. Jewell, A. V. S. Hill, J. McCluskey, J. Rossjohn, R. P. Anderson, Comprehensive, quantitative mapping of T cell epitopes in gluten in celiac disease., Sci. Transl. Med. 2, 41ra51 (2010).

17. A. R. Rishi, A. Rubio-Tapia, J. A. Murray, Refractory celiac disease, Expert Rev. Gastroenterol. Hepatol. 10, $537-546$ (2016).

18. M. M. Pietzak, Follow-up of patients with celiac disease: Achieving compliance with treatment, Gastroenterology 128, 135-141 (2005).

19. R. Bouziat, Reovirus infection triggers inflammatory responses to dietary antigens and development of celiac disease, 50, 44-50 (2017).

20. J. Petersen, L. Ciacchi, M. T. Tran, K. L. Loh, Y. Kooy-Winkelaar, N. P. Croft, M. Y. Hardy, Z. Chen, J. McCluskey, R. P. Anderson, A. W. Purcell, J. A. Tye-Din, F. Koning, H. H. Reid, J. Rossjohn, T cell receptor 
cross-reactivity between gliadin and bacterial peptides in celiac disease, Nat. Struct. Mol. Biol. 27, 49-61 (2020). 21. K. S. Gunnarsen, L. S. Høydahl, L. F. Risnes, S. Dahal-Koirala, R. S. Neumann, E. Bergseng, T. Frigstad, R. Frick, M. F. du Pré, B. Dalhus, K. E. A. Lundin, S.-W. Qiao, L. M. Sollid, I. Sandlie, G. Å. Løset, A TCR $\alpha$ framework-centered codon shapes a biased T cell repertoire through direct MHC and CDR3 $\beta$ interactions, JCI Insight 2 (2017), doi:10.1172/jci.insight.95193.

22. L. F. Risnes, A. Christophersen, S. Dahal-Koirala, R. S. Neumann, G. K. Sandve, V. K. Sarna, K. E. A. Lundin, S. W. Qiao, L. M. Sollid, Disease-driving CD4+T cell clonotypes persist for decades in celiac disease, J. Clin. Invest. 128, 2642-2650 (2018).

23. L. S. Høydahl, N. R. Nilssen, K. S. Gunnarsen, M. F. du Pré, R. Iversen, N. Roos, X. Chen, T. E. Michaelsen, L. M. Sollid, I. Sandlie, G. Å. Løset, Multivalent pIX phage display selects for distinct and improved antibody properties, Sci. Rep. 6, 39066 (2016).

24. B. J. Fennell, B. McDonnell, A. S. P. Tam, L. Chang, J. Steven, I. D. Broadbent, H. Gao, E. Kieras, J. Alley, D. Luxenberg, J. Edmonds, L. J. Fitz, W. Miao, M. J. Whitters, Q. G. Medley, Y. J. Guo, A. Darmanin-Sheehan, B. Autin, D. N. Sh??illeabh??in, E. Cummins, A. King, M. R. H. Krebs, C. Grace, T. P. Hickling, A. Boisvert, X. Zhong, M. McKenna, C. Francis, S. Olland, L. Bloom, J. Paulsen, W. Somers, A. Jensen, L. Lin, W. J. J. Finlay, O. Cunningham, CDR-restricted engineering of native human scFvs creates highly stable and soluble bifunctional antibodies for subcutaneous delivery, MAbs 5, 882-895 (2013).

25. L. Jespers, O. Schon, K. Famm, G. Winter, Aggregation-resistant domain antibodies selected on phage by heat denaturation, Nat. Biotechnol. 22, 1161-1165 (2004).

26. J. Rossjohn, S. Gras, J. J. Miles, S. J. Turner, D. I. Godfrey, J. McCluskey, T Cell Antigen Receptor Recognition of Antigen-Presenting Molecules, Annu. Rev. Immunol. 33, 169-200 (2015).

27. J. Petersen, V. Montserrat, J. R. Mujico, K. L. Loh, D. X. Beringer, M. van Lummel, A. Thompson, M. L. Mearin, J. Schweizer, Y. Kooy-Winkelaar, J. van Bergen, J. W. Drijfhout, W.-T. Kan, N. L. La Gruta, R. P. Anderson, H. H. Reid, F. Koning, J. Rossjohn, T-cell receptor recognition of HLA-DQ2-gliadin complexes associated with celiac disease, Nat. Struct. Mol. Biol. 21, 480-488 (2014).

28. M. C. Lawrence, P. M. Colman, Shape complementarity at protein/protein interfaces., J. Mol. Biol. 234, 946- 
50 (1993).

29. N. A. Baker, D. Sept, S. Joseph, M. J. Holst, J. A. McCammon, Electrostatics of nanosystems: Application to microtubules and the ribosome, Proc. Natl. Acad. Sci. U. S. A. 98, 10037-10041 (2001).

30. S.-W. Qiao, M. Ráki, K. S. Gunnarsen, G.-åge Løset, K. E. A. Lundin, I. Sandlie, L. M. Sollid, Posttranslational Modification of Gluten Shapes TCR Usage in Celiac Disease, J. Immunol. 187, 3064-3071 (2011)

31. G. Bentley, R. Higuchi, B. Hoglund, D. Goodridge, D. Sayer, E. A. Trachtenberg, H. A. Erlich, Highresolution, high-throughput HLA genotyping by next-generation sequencing., Tissue Antigens 74, 393-403 (2009).

32. L. Shan, Ø. Molberg, I. Parrot, F. Hausch, F. Filiz, G. M. Gray, L. M. Sollid, C. Khosla, Structural basis for gluten intolerance in celiac sprue., Science 297, 2275-2279 (2002).

33. L.-E. Fallang, E. Bergseng, K. Hotta, A. Berg-Larsen, C.-Y. Kim, L. M. Sollid, Differences in the risk of celiac disease associated with HLA-DQ2.5 or HLA-DQ2.2 are related to sustained gluten antigen presentation., Nat. Immunol. 10, 1096-1101 (2009).

34. S. Dahal-Koirala, L. F. Risnes, R. S. Neumann, A. Christophersen, K. E. A. Lundin, G. K. Sandve, S.-W. Qiao, L. M. Sollid, Comprehensive Analysis of CDR3 Sequences in Gluten-Specific T-Cell Receptors Reveals a Dominant R-Motif and Several New Minor Motifs, Front. Immunol. 12, 1-13 (2021).

35. M. F. du Pré, J. Blazevski, A. E. Dewan, J. Stamnaes, C. Kanduri, G. K. Sandve, M. K. Johannesen, C. B. Lindstad, K. Hnida, L. Fugger, G. Melino, S.-W. Qiao, L. M. Sollid, B cell tolerance and antibody production to the celiac disease autoantigen transglutaminase 2, J. Exp. Med. 217, 1-14 (2020).

36. A. E. Dewan, F. Koentgen, M. K. Johannesen, M. F. du Pre, L. M. Sollid, Generation of an HLA-DQ2.5 Knock-In Mouse., ImmunoHorizons 5, 25-32 (2021).

37. G. Å. Løset, I. Løbersli, A. Kavlie, J. E. Stacy, T. Borgen, L. Kausmally, E. Hvattum, B. Simonsen, M. B. Hovda, O. H. Brekke, Construction, evaluation and refinement of a large human antibody phage library based on the IgD and IgM variable gene repertoire., J. Immunol. Methods 299, 47-62 (2005).

38. C. J. Holland, R. M. Crean, J. M. Pentier, B. de Wet, A. Lloyd, V. Srikannathasan, N. Lissin, K. A. Lloyd, T. 
H. Blicher, P. J. Conroy, M. Hock, R. J. Pengelly, T. E. Spinner, B. Cameron, E. A. Potter, A. Jeyanthan, P. E. Molloy, M. Sami, M. Aleksic, N. Liddy, R. A. Robinson, S. Harper, M. Lepore, C. R. Pudney, M. W. van der Kamp, P. J. Rizkallah, B. K. Jakobsen, A. Vuidepot, D. K. Cole, Specificity of bispecific T cell receptors and antibodies targeting peptide-HLA, J. Clin. Invest. 130, 2673-2688 (2020).

39. L. Maiuri, C. Ciacci, I. Ricciardelli, L. Vacca, V. Raia, S. Auricchio, J. Picard, M. Osman, S. Quaratino, M. Londei, Association between innate response to gliadin and activation of pathogenic $\mathrm{T}$ cells in coeliac disease, Lancet 362, 30-37 (2003).

40. M. Ráki, S. Tollefsen, Ø. Molberg, K. E. a Lundin, L. M. Sollid, F. L. Jahnsen, A unique dendritic cell subset accumulates in the celiac lesion and efficiently activates gluten-reactive T cells., Gastroenterology 131, 428-38 (2006).

41. A.-C. R. Beitnes, M. Ráki, K. E. A. Lundin, J. Jahnsen, L. M. Sollid, F. L. Jahnsen, Density of CD163+ CD11c+ dendritic cells increases and CD103+ dendritic cells decreases in the coeliac lesion., Scand. J. Immunol. 74, 186-94 (2011).

42. A. C. R. Beitnes, M. Ráki, M. Brottveit, K. E. A. Lundin, F. L. Jahnsen, L. M. Sollid, Rapid accumulation of $\mathrm{CD} 14+\mathrm{CD} 11 \mathrm{c}+$ dendritic cells in gut mucosa of celiac disease after in vivo gluten challenge, PLoS One 7, 1-9 (2012).

43. A. Juhász, T. Belova, C. G. Florides, C. Maulis, I. Fischer, G. Gell, Z. Birinyi, J. Ong, G. Keeble-Gagnère, A. Maharajan, W. Ma, P. Gibson, J. Jia, D. Lang, K. F. X. Mayer, M. Spannagl, J. A. Tye-Din, R. Appels, O. A. Olsen, Genome mapping of seed-borne allergens and immunoresponsive proteins in wheat, Sci. Adv. 4 (2018), doi:10.1126/sciadv.aar8602.

44. T. Asledottir, R. Rehman, G. Mamone, G. Picariello, T. G. Devold, G. E. Vegarud, A. Røseth, T. E. Lea, T. S. Halstensen, P. Ferranti, A. K. Uhlen, Ancestral Wheat Types Release Fewer Celiac Disease Related T Cell Epitopes than Common Wheat upon Ex Vivo Human Gastrointestinal Digestion, Foods 9, 1173 (2020).

45. R. Di Niro, L. Mesin, N.-Y. Zheng, J. Stamnaes, M. Morrissey, J.-H. Lee, M. Huang, R. Iversen, M. F. du Pré, S.-W. Qiao, K. E. a Lundin, P. C. Wilson, L. M. Sollid, High abundance of plasma cells secreting transglutaminase 2-specific IgA autoantibodies with limited somatic hypermutation in celiac disease intestinal lesions, Nat. Med. 
18, 441-445 (2012).

46. Ø. Steinsbø, C. J. H. Dunand, M. Huang, L. Mesin, M. Salgado-Ferrer, K. E. A. Lundin, J. Jahnsen, P. C. Wilson, L. M. Sollid, Restricted VH/VL usage and limited mutations in gluten-specific IgA of coeliac disease lesion plasma cells, Nat. Commun. 5, 1-12 (2014).

47. L. Zhang, F. Crawford, L. Yu, A. Michels, M. Nakayama, H. W. Davidson, J. W. Kappler, G. S. Eisenbarth, Monoclonal antibody blocking the recognition of an insulin peptide-MHC complex modulates type 1 diabetes., Proc. Natl. Acad. Sci. U. S. A. 111, 2656-61 (2014).

48. R. Aharoni, D. Teftelbaum, R. Arnon, J. Puri, Immunomodulation of experimental allergic encephalomyelitis by antibodies to the antigen-Ia complex, Nature 351, 147-150 (1991).

49. A. D. Skora, J. Douglass, M. S. Hwang, A. J. Tam, R. L. Blosser, S. B. Gabelli, J. Cao, L. A. Diaz, N. Papadopoulos, K. W. Kinzler, B. Vogelstein, S. Zhou, Generation of MANAbodies specific to HLA-restricted epitopes encoded by somatically mutated genes., Proc. Natl. Acad. Sci. U. S. A. 112, 9967-72 (2015).

50. E. Klechevsky, M. Gallegos, G. Denkberg, K. Palucka, J. Banchereau, C. Cohen, Y. Reiter, Antitumor activity of immunotoxins with T-cell receptor-like specificity against human melanoma xenografts, Cancer Res. 68, 63606367 (2008).

51. J. R. Cepeda, N. S. Sekhar, J. Han, W. Xiong, N. Zhang, L. Yu, S. Dai, H. W. Davidson, J. W. Kappler, Z. An, L. Zhang, A monoclonal antibody with broad specificity for the ligands of insulin B:9-23 reactive T cells prevents spontaneous type 1 diabetes in mice., MAbs 12, 1836714 (2020).

52. N. R. Nilssen, T. Frigstad, S. Pollmann, N. Roos, B. Bogen, I. Sandlie, G. Å. Løset, DeltaPhage--a novel helper phage for high-valence pIX phagemid display., Nucleic Acids Res. 40, e120 (2012).

53. L.-E. Fallang, S. Roh, A. Holm, E. Bergseng, T. Yoon, B. Fleckenstein, A. Bandyopadhyay, E. D. Mellins, L. M. Sollid, Complexes of two cohorts of CLIP peptides and HLA-DQ2 of the autoimmune DR3-DQ2 haplotype are poor substrates for HLA-DM., J. Immunol. 181, 5451-5461 (2008).

54. W. Kabsch, Integration, scaling, space-group assignment and post-refinement, Acta Crystallogr. Sect. D Biol. Crystallogr. 66, 133-144 (2010).

55. N. 4 Collaborative Computational Project, The CCP4 suite: programs for protein crystallography., Acta 
Crystallogr. D. Biol. Crystallogr. 50, 760-3 (1994).

56. P. Emsley, K. Cowtan, Coot: model-building tools for molecular graphics., Acta Crystallogr. D. Biol. Crystallogr. 60, 2126-32 (2004).

57. P. D. Adams, R. W. Grosse-Kunstleve, L. W. Hung, T. R. Ioerger, A. J. McCoy, N. W. Moriarty, R. J. Read, J. C. Sacchettini, N. K. Sauter, T. C. Terwilliger, PHENIX: building new software for automated crystallographic structure determination., Acta Crystallogr. D. Biol. Crystallogr. 58, 1948-54 (2002).

58. B. D. Weitzner, J. R. Jeliazkov, S. Lyskov, N. Marze, D. Kuroda, R. Frick, J. Adolf-Bryfogle, N. Biswas, R. L. Dunbrack, J. J. J. Gray, Modeling and docking of antibody structures with Rosetta, Nat. Protoc. 12, 401-416 (2017).

59. N. A. Marze, J. J. Gray, Improved prediction of antibody VL-VH orientation, Protein Eng. Des. Sel. , 1-9 (2016).

60. P. Bradley, K. M. S. S. Misura, D. Baker, Toward High-Resolution de Novo Structure Prediction for Small Proteins, Science (80-. ). 309, 1868-1871 (2005).

61. K. M. S. Misura, D. Baker, Progress and challenges in high-resolution refinement of protein structure models, Proteins Struct. Funct. Genet. 59, 15-29 (2005).

62. B. D. Weitzner, J. J. Gray, Accurate structure prediction of CDR H3 loops enabled by a novel structure-based C-terminal “kink” constraint, J. Immunol. 2017 (2016), doi:10.4049/jimmunol.1601137.

63. A. Sircar, J. J. J. J. Gray, SnugDock: Paratope Structural Optimization during Antibody-Antigen Docking Compensates for Errors in Antibody Homology Models, PLoS Comput. Biol. 6, e1000644 (2010).

64. G. Å. Løset, E. Lunde, B. Bogen, O. H. Brekke, I. Sandlie, Functional phage display of two murine $\alpha / \beta$ T-cell receptors is strongly dependent on fusion format, mode and periplasmic folding assistance, Protein Eng. Des. Sel. 20, 461-472 (2007).

65. G. Å. Løset, N. Roos, B. Bogen, I. Sandlie, Expanding the versatility of phage display II: Improved affinity selection of folded domains on protein VII and IX of the filamentous phage, PLoS One 6 (2011), doi:10.1371/journal.pone.0017433.

66. R. Tonikian, Y. Zhang, C. Boone, S. S. Sidhu, Identifying specificity profiles for peptide recognition modules 
from phage-displayed peptide libraries., Nat. Protoc. 2, 1368-1386 (2007).

67. G. Å. Løset, B. Bogen, I. Sandlie, Expanding the versatility of phage display I: Efficient display of peptidetags on protein VII of the filamentous phage, PLoS One 6, 1-7 (2011).

68. K. S. Gunnarsen, E. Lunde, P. E. Kristiansen, B. Bogen, I. Sandlie, G. a Løset, Periplasmic expression of soluble single chain T cell receptors is rescued by the chaperone FkpA., BMC Biotechnol. 10, 8 (2010).

69. G. Berntzen, E. Lunde, M. Flobakk, J. T. Andersen, V. Lauvrak, I. Sandlie, Prolonged and increased expression of soluble Fc receptors, IgG and a TCR-Ig fusion protein by transiently transfected adherent 293E cells., J. Immunol. Methods 298, 93-104 (2005).

70. J. F. Ludvigsson, J. C. Bai, F. Biagi, T. R. Card, C. Ciacci, P. J. Ciclitira, P. H. R. Green, M. Hadjivassiliou, A. Holdoway, D. A. Van Heel, K. Kaukinen, D. A. Leffler, J. N. Leonard, K. E. A. Lundin, N. McGough, M. Davidson, J. A. Murray, G. L. Swift, M. M. Walker, F. Zingone, D. S. Sanders, Diagnosis and management of adult coeliac disease: Guidelines from the British society of gastroenterology, Gut 63, 1210-1228 (2014).

71. O. J. B. Landsverk, O. Snir, R. B. Casado, L. Richter, J. E. Mold, P. Réu, R. Horneland, V. Paulsen, S. Yaqub, E. M. Aandahl, O. M. Øyen, H. S. Thorarensen, M. Salehpour, G. Possnert, J. Frisén, L. M. Sollid, E. S. Baekkevold, F. L. Jahnsen, Antibody-secreting plasma cells persist for decades in human intestine, J. Exp. Med. 214, 309-317 (2017).

72. T. Straetemans, M. van Brakel, S. van Steenbergen, M. Broertjes, J. Drexhage, J. Hegmans, B. N. Lambrecht, C. Lamers, P. van Der Bruggen, P. G. Coulie, R. Debets, TCR gene transfer: MAGE-C2/HLA-A2 and MAGEA3/HLA-DP4 epitopes as melanoma-specific immune targets., Clin. Dev. Immunol. 2012, 586314 (2012).

73. M. Bodd, M. Ráki, E. Bergseng, J. Jahnsen, K. E. A. Lundin, L. M. Sollid, Direct cloning and tetramer staining to measure the frequency of intestinal gluten-reactive T cells in celiac disease, Eur. J. Immunol. 43, 2605-2612 (2013).

74. Ø. Molberg, N. S. Flæte, T. Jensen, K. E. A. Lundin, H. Arentz-Hansen, O. D. Anderson, A. Kjersti Uhlen, L. M. Sollid, Intestinal T-cell responses to high-molecular-weight glutenins in celiac disease, Gastroenterology $\mathbf{1 2 5}$, $337-344$ (2003).

75. D. J. Mathis, C. Benoist, V. E. Williams, M. Kanter, H. O. McDevitt, Several mechanisms can account for 
defective E alpha gene expression in different mouse haplotypes., Proc. Natl. Acad. Sci. U. S. A. 80, 273-277 (1983). 

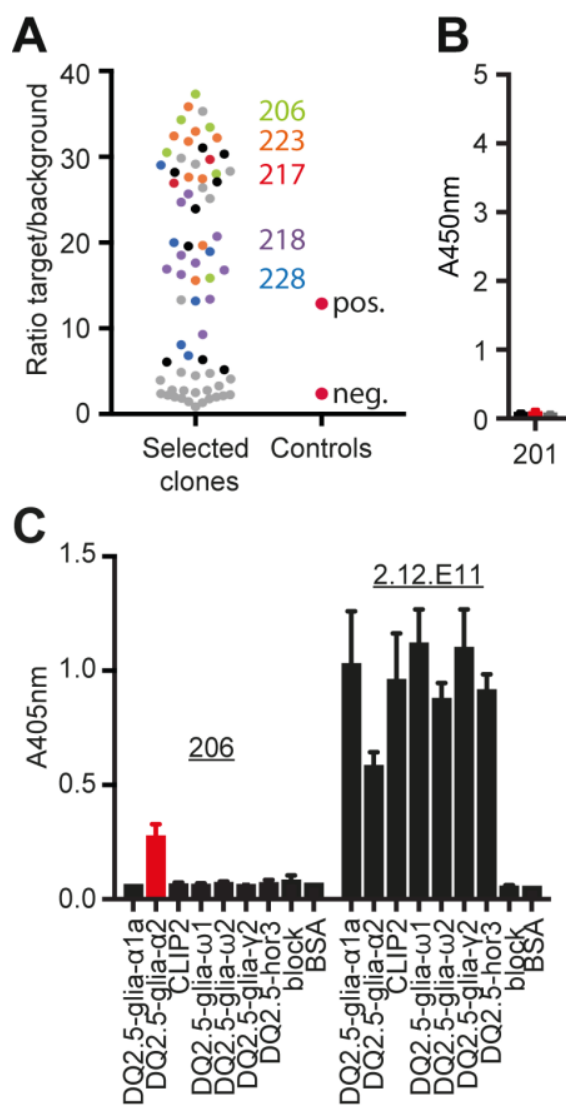

B
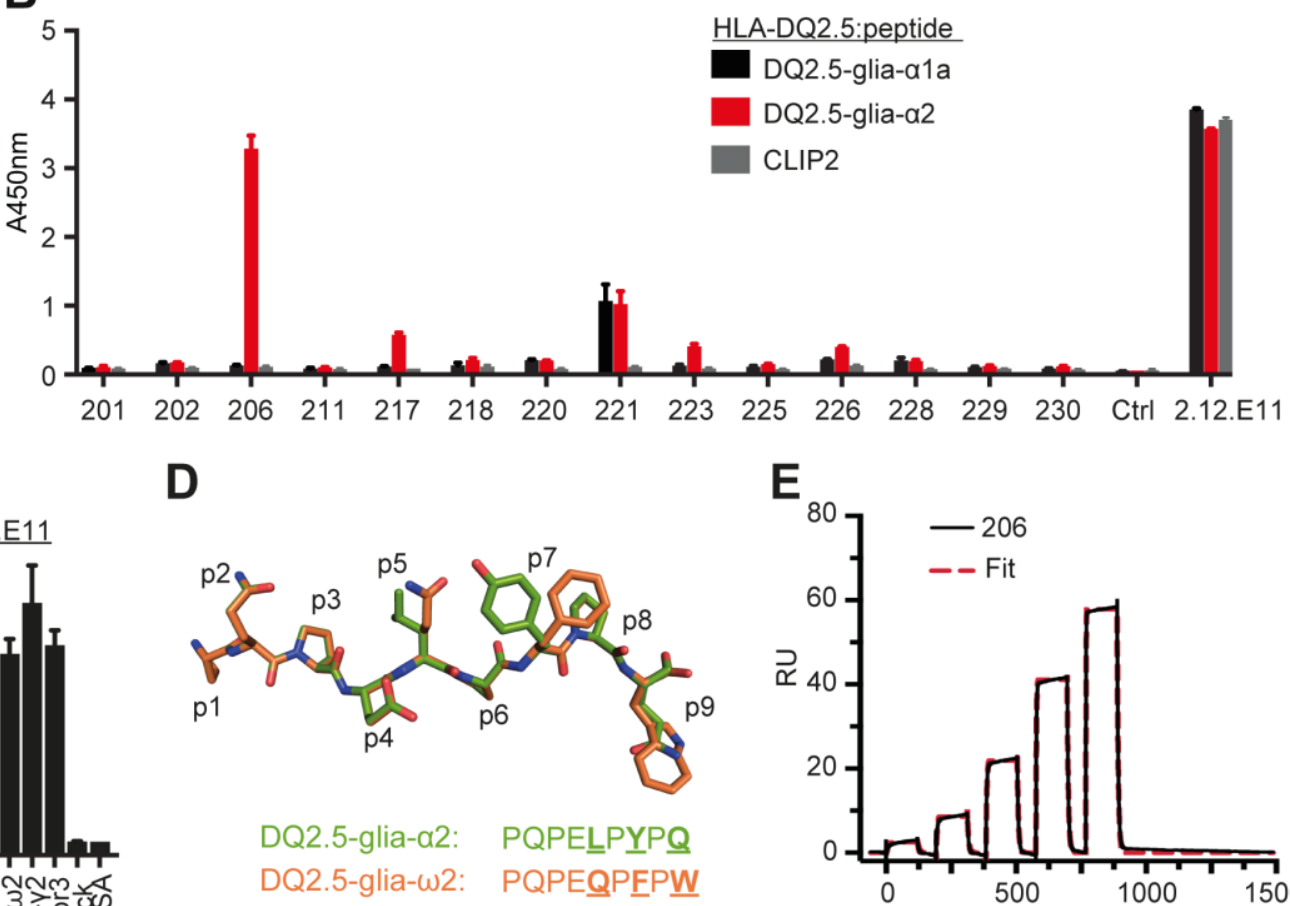

E

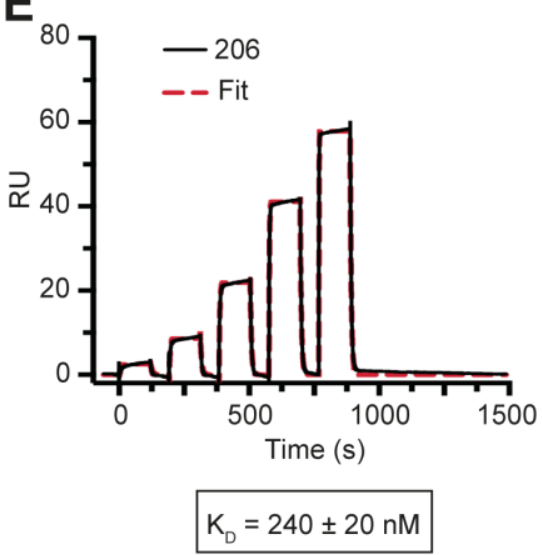

Fig. 1. Isolation and characterization of an antibody specific for HLA-DQ2.5:DQ2.5-glia- $\alpha 2$. (A) The selection output after three rounds of selection was batch cloned into a vector for soluble $\mathrm{scFv}$ expression and single colonies were expressed in the $E$. coli periplasm followed by screening for binding to HLA-DQ2.5:DQ2.5-glia- $\alpha 2$ (target) and HLA-DQ2.5:CLIP2 (background) in ELISA. ScFv anti-phOx binding to BSA-phOx and empty E. coli were included as positive and negative controls, respectively. The ratios of target/background binding are represented as dots for each clone. Positive clones were sequenced, and colors represent clones found repeatedly. Grey dots denote clones with unknown sequence. (B) 14 unique clones were expressed, and periplasmic fractions were analyzed for binding to related gluten pMHC complexes in ELISA. E. coli XL1-Blue were included as a negative control (ctrl) and pMHC capture levels were controlled with the HLADQ2 antibody 2.12.E11. Error bars illustrate mean \pm SD of duplicates $(n=2)$. (C) The lead candidate 206 was reformatted to hIgG1 and binding to a larger peptide panel of pMHC complexes was tested in ELISA. Error bars illustrate mean \pm SD of duplicates ( $\mathrm{n}=2)$. (D) Structural alignment of DQ2.5-glia- $\alpha 2$ (PDB code 4OZH (27)) and the related DQ2.5-glia- $\omega 2$ epitope (model). Differing positions are underlined. (E) The monomeric affinity of Fab 206 for HLA-DQ2.5:DQ2.5-glia- $\alpha 2$ was determined by SPR using single cycle kinetics and fitting a 1:1 binding model to the data ( $\mathrm{n}=2$, representative sensorgram shown). 


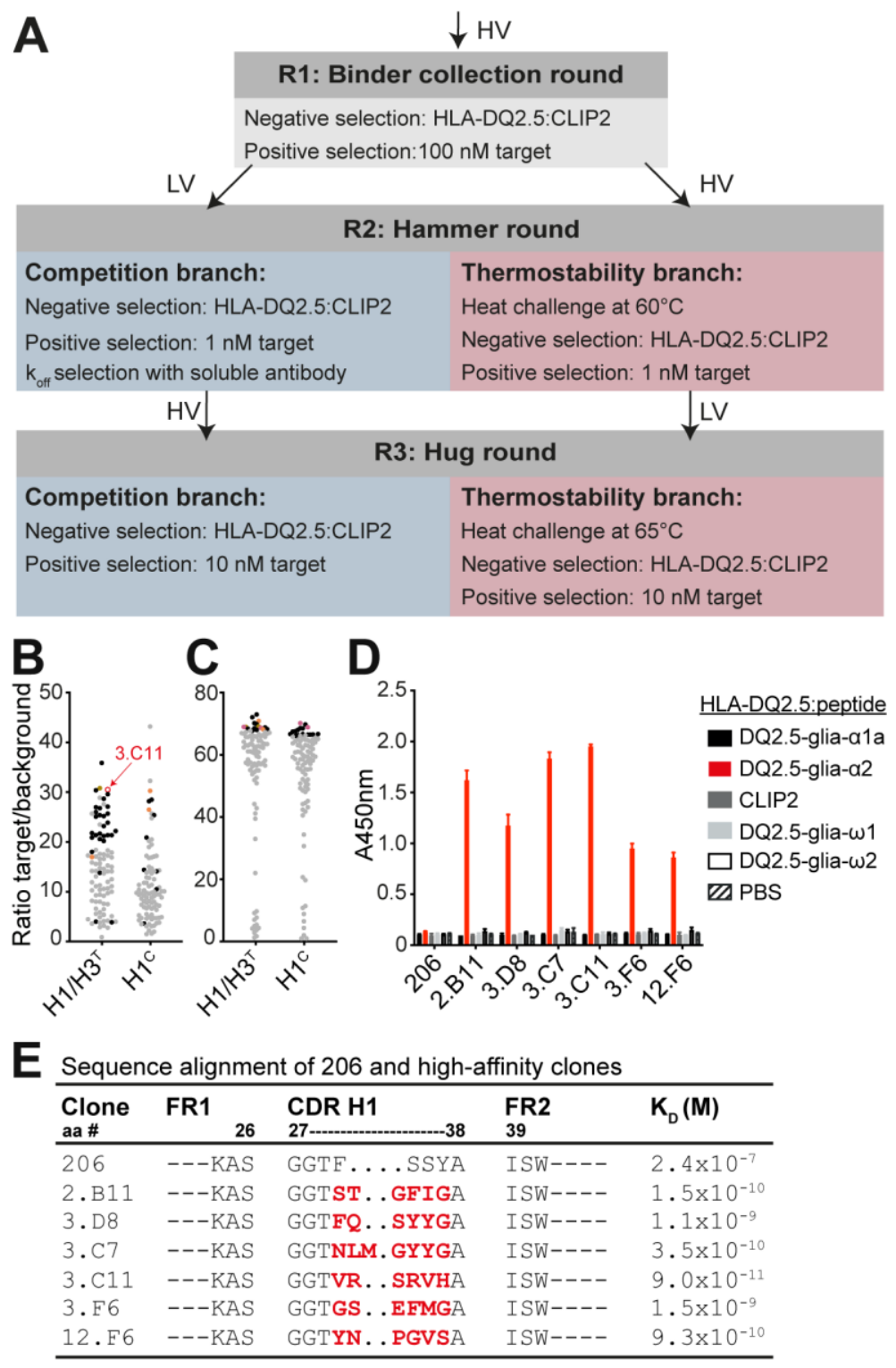

Fig. 2. Selection and screening of antibody libraries. (A) Schematic overview of the selection strategy. Low valence (LV) and high valence (HV) display were achieved by packaging with the helper phages M13K07 or DeltaPhage, respectively. After R1 the libraries were split into a competition branch and a thermostability branch. (B) The selection outputs after R3 were screened as soluble scFvs to assess binding to target pMHC and HLA-DQ2.5:CLIP2 (background) in ELISA and ratios were calculated. Each dot represents one clone. Grey dots denote unknown sequences, black dots denote unique single sequences and colors represent enriched amino acid sequences. The H1/H3 ${ }^{\mathrm{T}}$ library containing pooled CDR $\mathrm{H} 1$ and $\mathrm{H} 3$ libraries was selected in the thermostability branch, while the $\mathrm{H}^{\mathrm{C}}$ library (CDR $\mathrm{H} 1$ only) was selected in the competition branch. (C) The R3 selection outputs were screened in phage format and are represented as in B. (D) Purified, monomeric Fab fragments were tested for binding to a panel of HLA-DQ2.5:peptide complexes in ELISA. Error bars illustrate mean \pm SD of duplicates ( $\mathrm{n}=2$ ). (E) Sequence alignment of the mother clone 206 and the high-affinity offspring containing CDR H1 mutations (bold red). IGHV gene segment usage and numbering according to the IMGT scheme. The IGHVI-69 V gene of clone 206 is in germline configuration. 

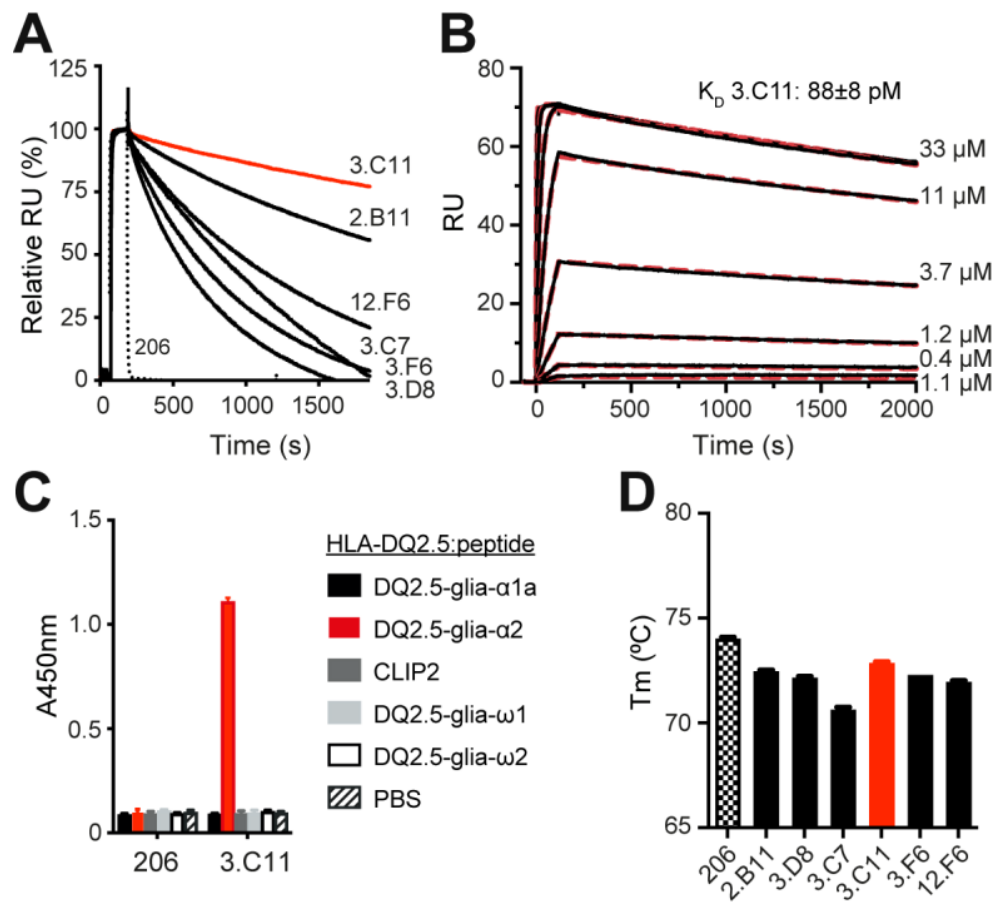

Fig. 3. Biophysical characterization of leads. (A) Fab fragments were ranked based on off-rates in SPR with the lead clone 3.C11 highlighted in red and the parent clone using dotted lines $(n=2)$. (B) Representative sensorgrams of Fab 3.C11 (n=3). (C) 3.C11 was reformatted to full-length hIgG1 and analyzed in ELISA against a panel of related soluble peptide:HLA-DQ2.5 complexes. Error bars illustrate mean \pm SD of duplicates (n=3). (D) Melting temperatures of mother clone Fab 206 (squared) and the affinity matured Fab fragments with the lead candidate 3.C11 highlighted in red. Error bars illustrate mean \pm SD of triplicates $(n=1)$. 


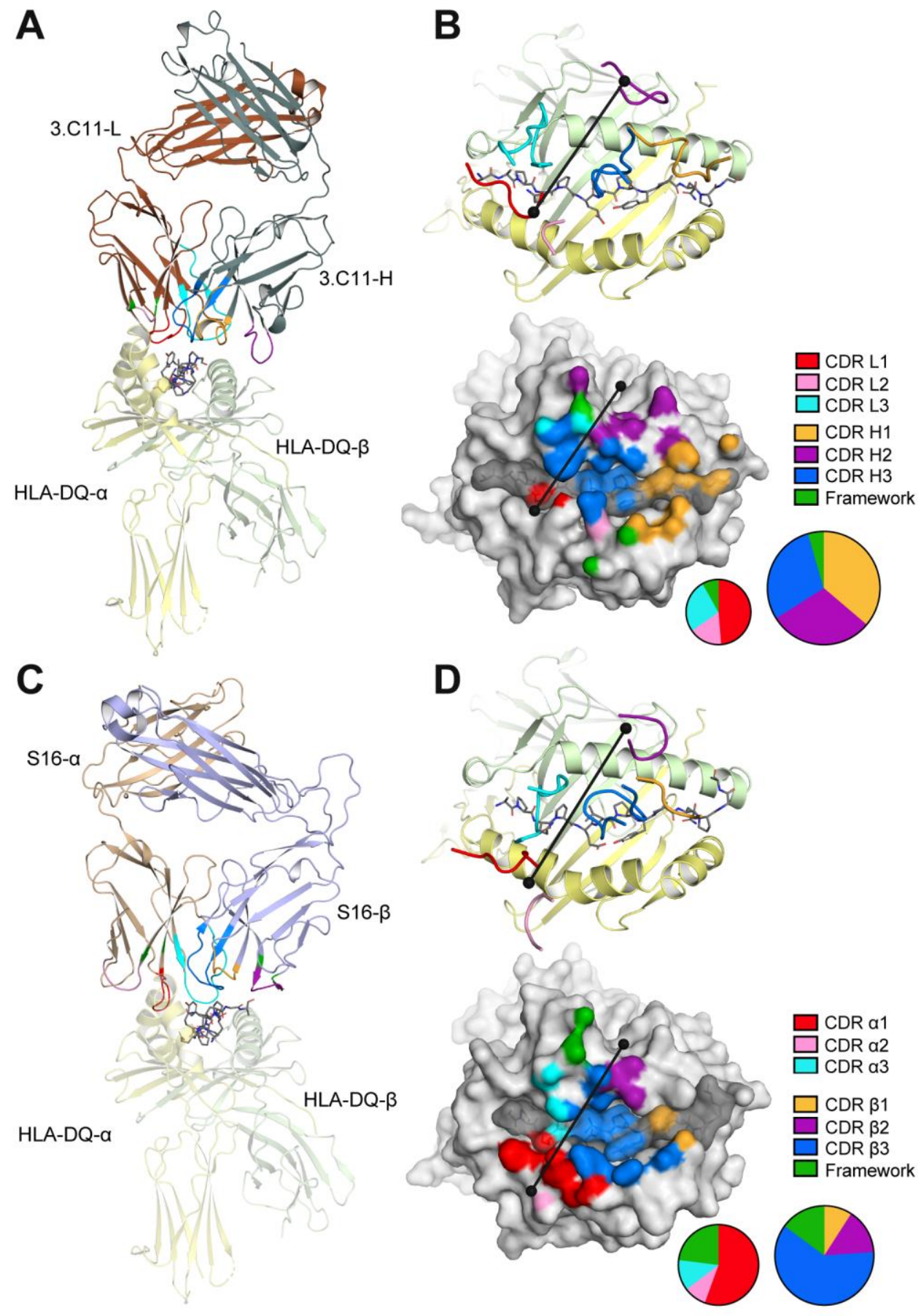

Fig. 4. TCR-like binding mode of 3.C11 to HLA-DQ2.5:DQ2.5-glia- $\alpha 2$. (A) Overview of the Fab 3.C11 - HLA-DQ2.5:DQ2.5-glia- $\alpha 2$ complex. HLA-DQ2.5 $\alpha$ - and $\beta$-chains are light green and light yellow, respectively; the peptide is dark grey and shown in stick 
representation; 3.C11 $\mathrm{H}$ - and L-chains are brown and grey, respectively. CDRs and framework are colored as indicated in the figure. (B) CDR loop arrangement (top) and footprint (bottom) of the Fab 3.C11 - HLA-DQ2.5:DQ2.5-glia- $\alpha 2$ complex. In the footprint, HLADQ2.5:HLA-DQ2.5-glia- $\alpha 2$ is shown in surface representation with the peptide in dark grey. Atoms contacted by the Fab are colored according to the nearest CDR loop or framework residue. Black dots and line represent the center of mass positions of the antibody variable domains and illustrate the approximate docking angle. (C) Overview and (D) CDR loop arrangement and footprint of the TCR S16 - HLADQ2.5:DQ2.5-glia- $\alpha 2$ complex illustrated for comparison (27). 

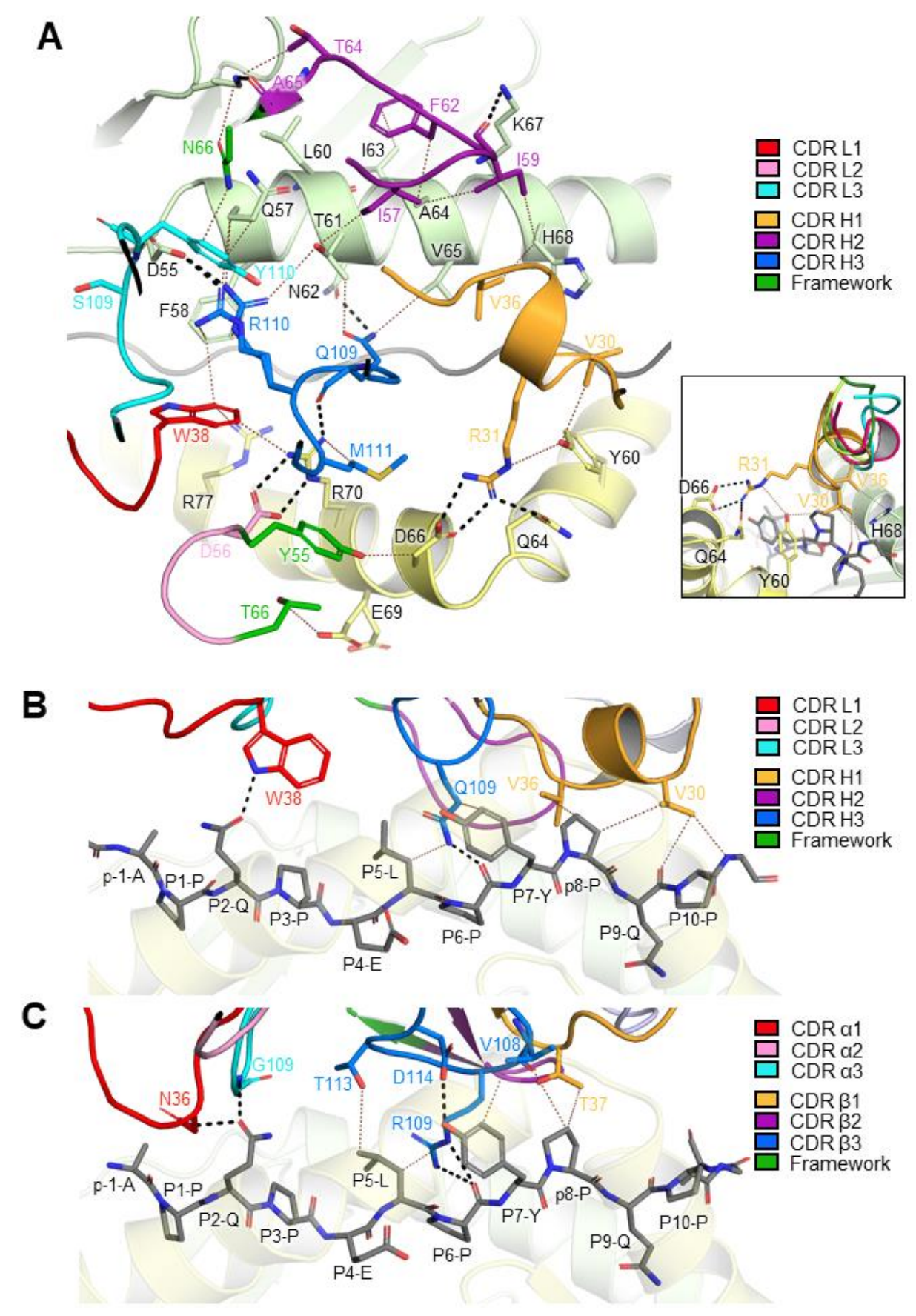

Fig. 5. TCR-like features in the HLA-DQ2.5:DQ2.5-glia-a2 binding interface of 3.C11. (A) Interactions of the Fab 3.C11 with HLADQ2.5 $\alpha$ - and $\beta$-chains (light green and light yellow, respectively). CDRs and framework are colored as indicated in the figure with interacting residues represented as sticks. The peptide is shown in grey. Black dashes, hydrogen bonds and salt bridges; dotted lines, van der Waals interactions. All amino acids are indicated by their single-letter abbreviations. Box inset: Overlay of the 3.C11 CDR H1 (orange) 
with canonical IGHV1-69 CDR H1 from published structures (PDB codes green, 5WL2; cyan, 5I18; lime, 6O41; pink, 5J74). (B) Interactions of the Fab 3.C11 with the DQ2.5-glia- $\alpha 2$ peptide. (C) Interactions of the TCR S16 with the DQ2.5-glia- $\alpha 2$ peptide (27). 

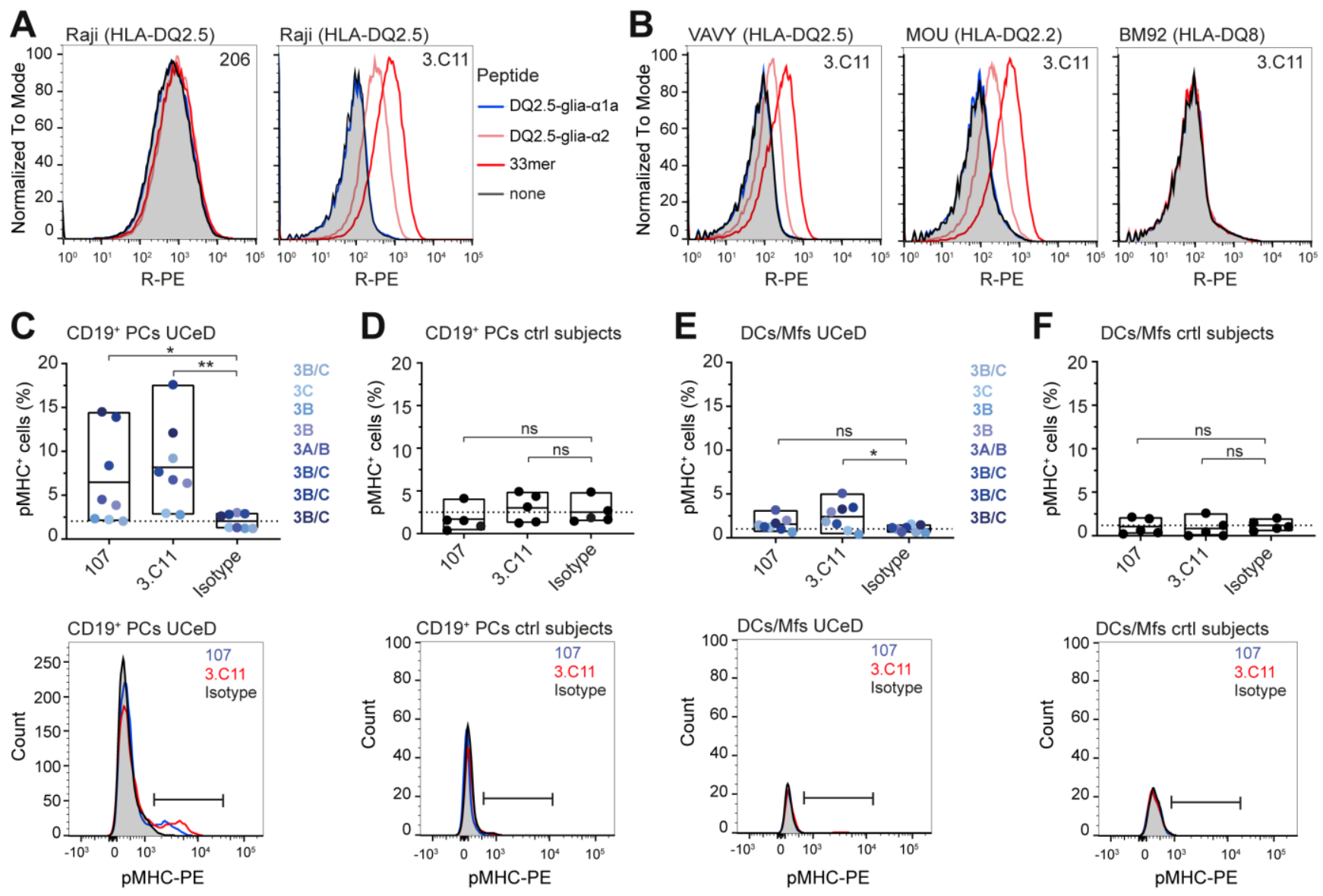

Fig. 6. 3.C11 binds peptide-loaded cells and detects gluten peptide presentation on cells from CeD patient biopsies. (A) Raji B cells were in vitro loaded with gluten peptides as annotated and stained with R-PE-conjugated 206 or $3 . \mathrm{C} 11 \mathrm{mIgG} 2 \mathrm{~b}$ ( $\mathrm{n}=1)$ (B) Human EBV transduced B-cell lines expressing different HLA-DQ allotypes were loaded with gluten peptides and stained with 3.C11 as before ( $\mathrm{n}=2$ ). (C-F) Single-cell suspensions were prepared from untreated HLA-DQ2.5 ${ }^{+} \mathrm{CeD}$ patients $(\mathrm{n}=8$, UCeD) or controls with a normal intestinal histology $\left(\mathrm{n}=5\right.$, two of the controls were HLA-DQ2.5 $5^{+}$. PCs were gated as live, large lymphocytes, $\mathrm{CD} 3{ }^{-} \mathrm{CD} 11 \mathrm{c}^{-} \mathrm{CD} 14^{-} \mathrm{CD} 38^{+} \mathrm{CD} 27^{+/-}$ $\mathrm{CD}_{19}{ }^{+} \mathrm{CD} 45^{+}$cells $(\mathrm{C}, \mathrm{D})$, and DCs/Mfs as live, CD3-CD19-CD27-CD38-CD11 ${ }^{+} \mathrm{CD} 14^{+}$cells (E, F). Cells were stained with mIgG2b antibodies followed by a PE-conjugated secondary antibody. Frequency of positive cells was calculated based on gates set according to the staining of an isotype control antibody (isotype). Upper panels; percentage of $\mathrm{pMHC}^{+}$cells across individuals. Boxes illustrate minimum to maximum value with the middle line at mean percentage. Dotted lines represent mean background staining of the isotype. For each CeD subject (different shades of blue), alterations in biopsy histology according to modified Marsh scores are indicated. Statistical differences between groups were analyzed using an unpaired two-tailed $t$-test. ${ }^{*} P<0.05 ; * * P<0.01 ; * * * P<0.001 ; * * * * P<0.0001$; ns, not significant. Lower panels; representative histograms showing pMHC-specific staining within patient groups as indicated. 

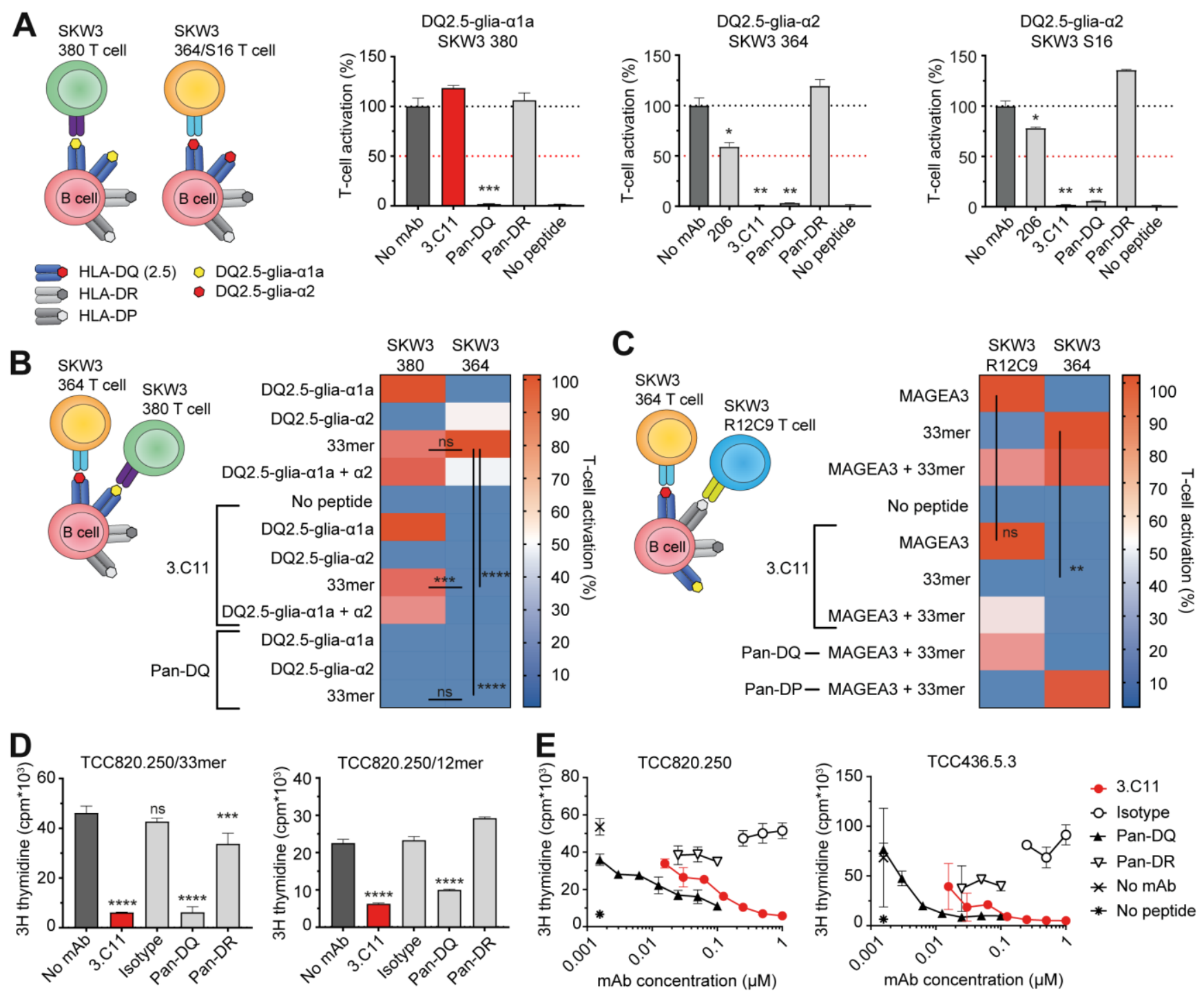

Fig. 7. Inhibitory capacity of the HLA-DQ2.5:DQ2.5-glia- $\alpha$-specific antibody 3.C11. (A) pMHC-specific antibodies (1 $\mu$ M) or pan-

HLA antibodies $(0.1 \mu \mathrm{M})$ were added to peptide-loaded Raji B cells prior to incubation with T cells. T-cell activation (CD69 upregulation) was calculated relative to T-cell activation without presence of antibodies. Error bars illustrate mean \pm SD of duplicates ( $\mathrm{n}=3$ ). (B and C) Raji B cells were loaded with gluten peptides or combinations of them and co-cultured with a blend of SKW3 380 and 364 T-cells (B, $\mathrm{n}=2$ ), or K562-CIITA cells were loaded with stimulatory peptides or combinations of them and co-cultured with a blend of the SKW3 364 and R12C9 T-cells (C, n=3). In both panels, SKW3 $364 \mathrm{~T}$ cells were labelled with CFSE to guide T-cell separation in flow analysis. Presence or absence of antibodies is indicated. Signals were normalized to antigen-specific activation in absence of antibodies and the heatmap represents means of duplicates. (D) The primary T-cell clone (TCC) specific for HLA-DQ2.5:DQ2.5-glia- $\alpha 2$, TCC820.250, was co-cultured with peptide-loaded Raji B cells in presence of antibodies as annotated. T-cell proliferation was assessed in a $3 \mathrm{H}$-thymidine incorporation assay. Error bars represent mean \pm SD of triplicates (n=2). (E) HLA-DQ2.5:DQ2.5-glia- $\alpha 2$-specific TCCs (TCC820.250 and TCC436.5.3) were co-cultured with 33mer-loaded Raji B cells in presence of titrated amounts of antibodies as annotated. Pan-HLA- 
DQ antibody (SPV-L3), pan-HLA-DR antibody (L243 or B8.11), pan-HLA-DP antibody (B7/21), and an isotype were included as controls. Error bars represent mean $\pm \mathrm{SD}$ of triplicates $(\mathrm{n}=2 / 3)$. Statistical differences between groups were analyzed using an unpaired two-tailed $t$ test. $* P<0.05 ; * * P<0.01 ; * * * P<0.001 ; * * * * P<0.0001$; ns, not significant. 


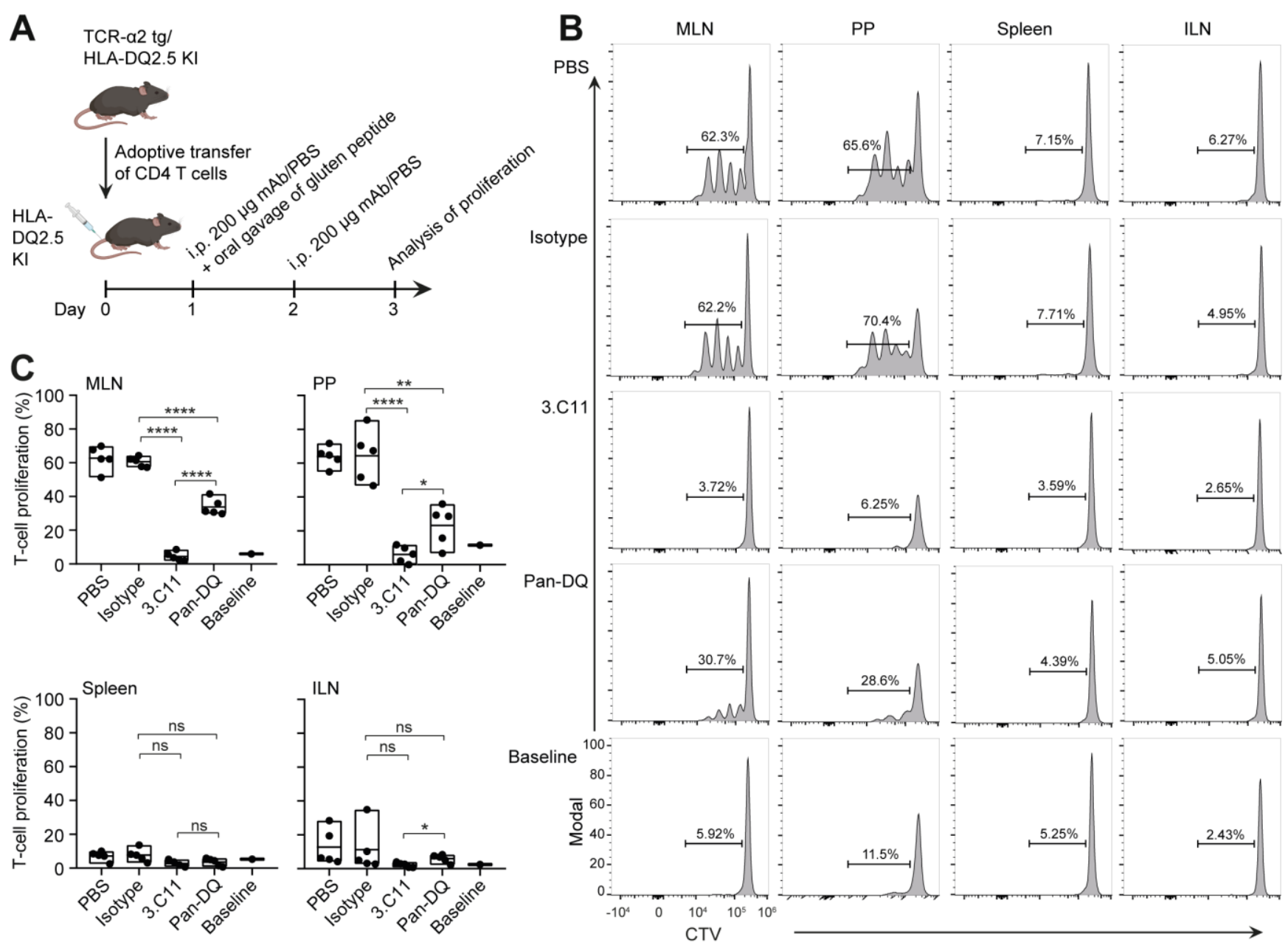

Fig. 8. Inhibition of T-cell proliferation by 3.C11 in HLA-DQ2.5 humanized mice. The ability of mAb 3.C11 to block in vivo T-cell activation was evaluated by measuring the percentage of proliferating T-cells in an adoptive transfer model. (A) Schematic overview of the adoptive transfer model. HLA-DQ2.5:DQ2.5-glia- $\alpha 2$-specific T cells isolated from TCR tg mice were labeled with Cell Trace Violet (CTV) prior to transfer into HLA-DQ2.5 KI mice. The following day, mice first received an i.p. dose of mAb or PBS alone, before intragastric gavage of $100 \mu \mathrm{g}$ deamidated gluten peptide after $30 \mathrm{~min}$. Mesenteric lymph nodes (MLN), Peyer's patches (PP), spleen and inguinal lymph nodes (ILN) were harvested $48 \mathrm{~h}$ after peptide administration and analyzed for T-cell proliferation. (B) Representative histograms showing T-cell proliferation by measuring dilution of fluorescent dye. 5 mice per group received i.p. injection of antibody (either mIgG2b 3.C11, mIgG2b isotype control or mIgG2a SPV-L3) or PBS in two independent experiments, with the exception of the $3 . \mathrm{C} 11$ group containing 4 mice due to a technical issue. One mouse received neither i.p. injection nor oral peptide (denoted baseline). Percentage proliferating cells are indicated in each panel. (C) Percentage of proliferating T-cells in the MLN, PP, spleen and ILN in mice receiving i.p. administration of antibody or PBS, or the untreated baseline mouse. Each data point represents an individual mouse. Boxes illustrate minimum to maximum value with the middle line at mean. Statistical differences between two groups were analyzed using an unpaired two-tailed $t$-test. $* P<0.05 ; * * P<0.01 ; * * * P<0.001 ; * * * * P<0.0001$; ns, not significant. 


\section{Supplementary Materials and Methods}

\section{Recombinant $P M H C$ expression and purification}

Recombinant, soluble pMHC with the peptides DQ2.5-glia- $\alpha 1$ (aLQPFPQPELPY), DQ2.5-glia- $\alpha 2$ (PQPELPYPQPE), CLIP2 (MATPLLMQALPMGAL), DQ2.5-glia- $\omega 1$ (QQPFPQPEQPFP), DQ2.5-glia- $\omega 2$ (FPQPEQPFPWQP), DQ2.5-glia- $\nu 2$ (QGIIQPEQPAQL), and DQ2.5-hor-3 (EQPIPEQPQPYP) covalently linked to the MHC $\beta$-chain (linker GAGSLVPRGSGGGGS) were produced in insect cells and affinity purified using the monoclonal antibody 2.12.E11 as previously described (53). The recombinant pMHC molecules were biotinylated in a site-specific manner using the enzyme BirA. If used for SPR, monomeric proteins were isolated by size exclusion chromatography using a Superdex 200. For crystallisation and structure determination of the 3.C11 DQ2.5-glia- $\alpha 2$ complex, pMHC with a modified DQ2.5-glia- $\alpha 2$ peptide (APQPELPYPQP) and linker (GSGGSIEGRGGSGAS) was expressed in Hi5 insect cells and purified as previously described (27). Briefly, media was buffer exchanged and pMHC purified via Niaffinity and S200 gel filtration chromatography, and the C-terminal fos/jun dimerisation domain was removed via enterokinase cleavage followed by Hitrap-Q anion exchange chromatorgaphy. Subsequently, HLA DQ2.5-glia$\alpha 2$ was incubated with an equimolar amount of 3.C11, and the complex was concentrated to $8 \mathrm{mg} / \mathrm{ml}$ following a final S200 gel filtration step.

\section{Crystallisation data collection and structure determination}

Crystals of the 3.C11 - HLA DQ2.5-glia- $\alpha 2$ complex were grown via the sitting drop vapor diffusion method in mother liquor composed of equal volumes of protein and reservoir solution containing $10 \%(\mathrm{w} / \mathrm{v})$ PEG 4000, 20\% (w/v) 2-propanol and 0.1M HEPES (pH7.5). Plate-like crystals were obtained after several weeks, and crystals were transferred into reservoir solution supplemented with $20 \%(w / v)$ glycerol, prior to freezing in liquid N2 for data collection. X-ray diffraction data was collected at the MX2 beamline of the Australian Synchrotron and merged using the local implementation of XDS (54) and AIMLESS of the CCP4 package (55). The structure was solved via molecular replacement in Phaser using single protomers from PDB files 5JO4 and 6MFG. Model building and structure refinement was performed using Coot (56) and the PHENIX package (57), respectively. Structural figures were prepared using Pymol.

\section{Antibody modeling}

Structural models of the Fv fragment were generated as described $(9,58)$. CDR loops and framework region templates were selected by sequence homology and combined to produce a single "grafted" model using RosettaAntibody. We used 10 templates for the $V_{L} / V_{H}$ relative orientation (59) resulting in 10 grafted models. 
The grafted models were then energy minimized (relaxed) in the Rosetta score function $(60,61)$ and further improved by de novo CDR H3 loop modeling and $\mathrm{V}_{\mathrm{L}} / \mathrm{V}_{\mathrm{H}}$ docking. The CDR H3 loop was constrained to a kinked conformation (62) and a total of 2,800 Fv models were generated. The 10 final models were selected based on low Rosetta score and $V_{L} / V_{H}$ orientations within the natural distribution. Models were taken from at least three initial grafted templates to maintain diversity.

\section{Antibody docking to $\mathrm{PMHC}$}

We used the cocrystal structure of a T-cell receptor (4OZI) (27) as a template for an initial orientation of the Fv model relative to the PMHC. A crystal structure of HLA-DQ2.5:DQ2.5:glia- $\alpha 2$ (4OZF) (27) was retrieved from the PDB and relaxed in the Rosetta score function. Combining the HLA structure with an ensemble of 10 final Fv models, we used SnugDock to generate 1,000 complex models, as described in (63). The final models were ranked and selected based on low Rosetta interface score, occurrence of "energy funnels" (i.e. structurally similar models separated from the bulk of models by a decrease in score), and an agreement with the experimental observations.

\section{Primary phage display selection}

The HLA-DQ2.5:DQ2.5-glia- 22 -specific mother clone 206 was isolated from a naïve fully human scFv library reformatted to the phagemid vector pFKPDN (64). The selection protocol was essentially as described in $(9,23)$. Phage input in R1 was $1.0 \times 10^{11} \mathrm{cfu}^{\mathrm{ampR}}$. A total of three rounds of selection were performed. Phage libraries, beads and tubes were alternating blocked with 5\% skim milk (R1 and 3) or $2 \%$ BSA (R2) in PBS supplemented with $0.05 \%$ tween-20 (PBS-T) prior to each round of selection. Blocked phages were incubated with biotinylated HLA-DQ2.5:CLIP2 (negative selection) in volumes of $1 \mathrm{~mL}$ PBS-T in $1.5 \mathrm{~mL}$ tubes on a rotating wheel for $1 \mathrm{~h}$ at room temperature and removed bound phages with streptavidin-coated magnetic beads (Dynabeads MyOne Streptavidin T1, Invitrogen). Next, phage libraries were selected on biotinylated HLA-DQ2.5:DQ2.5-glia- $\alpha 2$ with decreasing concentrations of $160 \mathrm{nM}, 16 \mathrm{nM}$ and $1.6 \mathrm{nM}$ from R1 to R3 before immobilization on magnetic beads. Bound phage particles where washed with PBS-T and PBS (5+5 washes in R1, 10+10 washes in R2 and 20+20 washes in R3 of selection). Phages were eluted by incubation in $500 \mu \mathrm{L} 0.5 \%$ trypsin (Gibco) and incubation at room temperature on a rotating wheel for $10 \mathrm{~min}$. Half of the eluted phage were used for infection of $50 \mathrm{~mL}$ cultures of fresh log-phase $E$. coli SS320 in 2x YT medium supplemented with $30 \mu \mathrm{g} / \mathrm{mL}$ tetracycline, $0.15 \mathrm{M}$ glucose $\left(2 \mathrm{x}\right.$ YT-TG) at $37^{\circ} \mathrm{C} / 80 \mathrm{rpm} / 30 \mathrm{~min}$. E. coli were pelleted, resuspended in $1 \mathrm{~mL} 2 \mathrm{x}$ YT and plated onto LB-

agar Bio-Assay dishes (245 mm x $245 \mathrm{~mm}$, Nunc) supplemented with $30 \mu \mathrm{g} / \mathrm{mL}$ tetracycline, $100 \mathrm{\mu g} / \mathrm{mL}$ ampicillin, and $0.1 \mathrm{M}$ glucose (LB-TAG) as above and grown at $30^{\circ} \mathrm{C} / 16 \mathrm{~h}$. E. coli were scraped and reinoculated to OD 0.05 
in $2 x$ YT-TAG and grown at $37^{\circ} \mathrm{C} / 200 \mathrm{rpm}$ until OD reached 0.1-0.2. Cultures were superinfected with helper phages M13KO7 for low valence display or HyperPhage for high valence display at $\mathrm{MOI} 10$. Cells were incubated $37^{\circ} \mathrm{C} / 30 \mathrm{~min} / 80 \mathrm{rpm}$ followed by $37^{\circ} \mathrm{C} / 30 \mathrm{~min} / 200 \mathrm{rpm}$. Medium was then changed to $2 \mathrm{x} \mathrm{YT}$ supplemented with $100 \mathrm{\mu g} / \mathrm{mL}$ ampicillin and $50 \mathrm{\mu g} / \mathrm{mL}$ kanamycin (2x YT-AK) and phage were packaged at $37^{\circ} \mathrm{C} / 200 \mathrm{rpm} / 7 \mathrm{~h}$. Cells

were pelleted, and supernatants filtered $(0.22 \mu \mathrm{m})$ and $\mathrm{PEG} / \mathrm{NaCl}$ precipitated overnight $(\mathrm{ON})$, before resuspension in PBS.

\section{Screening of primary selection output}

Screening of selection output was done after batch cloning the selection output into pFKPEN (64) for soluble scFv expression as indicated. 96 clones from the R3 output were picked into a 96-deep-well plate containing $400 \mu \mathrm{L}$ 1x LB-AG and incubated at $37^{\circ} \mathrm{C}$ ON shaking. $50 \mu \mathrm{L}$ of ON cultures were transferred to a fresh 96-deep-well plate containing $400 \mu \mathrm{L} 1 \times \mathrm{LB}-\mathrm{AG}$ and incubated $4 \mathrm{~h} / 37^{\circ} \mathrm{C} / 600 \mathrm{rpm}$. Cells were harvested by centrifugation and resuspended in $450 \mu \mathrm{L} 2 \mathrm{x}$ YT-A supplemented with $0.1 \mathrm{mM}$ IPTG. Plates were incubated at $30{ }^{\circ} \mathrm{C} / \mathrm{ON} / 600 \mathrm{rpm}$. Cells were harvested and supernatant samples were taken. Periplasmic fractions were extracted on ice/1 h using $300 \mu \mathrm{L}$ of $50 \mathrm{mM}$ Tris- $\mathrm{HCl}, 20 \%$ sucrose, $1 \mathrm{mM}$ EDTA, pH 8, $1 \mathrm{mg} / \mathrm{mL}$ lysozyme, and $0.1 \mathrm{mg} / \mathrm{mL}$ RNaseA. Cells were pelleted and periplasmic samples taken and blended 1:1 with supernatant samples for use in ELISA.

\section{Generation of targeted scFv phage libraries}

The second generation libraries were based on the scFv sequence of the parent clone 206 in pGALD9LLFN (65). A modified version of a previously described protocol was employed to generate the targeted libraries (66), now including a preparative step to remove template background, and a lower concentration of DNA in transformation to minimize multiple genotypes per cell during initial library packaging. Briefly, Agel restriction enzyme sites were introduced into the target sequences using mutagenic oligonucleotides and a standard PCR protocol. Mother clone phage containing the Agel sites were packaged from E. coli XL1-Blue by superinfection with M13K07 (MOI 10) and precipitated with PEG/NaCl (20\% w/v PEG 8,000, $2.5 \mathrm{M} \mathrm{NaCl).} \mathrm{Single-stranded} \mathrm{(ss)}$ DNA was isolated from phage suspensions using a QIAprep Spin M13 kit and verified with agarose gel electrophoresis. 8 sets of mutagenic oligonucleotides with 6-7 degenerate NNK codons (N: A/C/G/T, K: T/G) were designed so that they target relevant stretches of the $\mathrm{CDR} \mathrm{H1}$ or $\mathrm{H} 3$ loops for randomization and length variation. Specifically, the length of the CDR H1 was increased by 2 or 3 residues and the CDR H3 length was increased by 1 or 2 residues. The oligonucleotides were 5'-phosphorylated and annealed to the ssDNA. Heteroduplex DNA was synthesized using T7 DNA polymerase and ligated with T4 DNA ligase. Covalently closed circular double-stranded DNA was purified by agarose gel electrophoresis and transformed into electrocompetent $E$. coli AVB100FmkII 
(67) using a BTX ECM 600. Transformants were plated onto LB-TAG agar Bioassay dishes (245 mm x $245 \mathrm{~mm}$, Nunc) and grown at $30^{\circ} \mathrm{C} / 16 \mathrm{~h}$. Primary transformations were spot titrated onto nitrocellulose membranes and the number of primary transformants for the CDR H1 and CDR H3 libraries were estimated to $4.1 \times 10^{9}$ and $1.2 \times 10^{9}$ unique clones, respectively. Plates were scraped and DNA was isolated and digested with Agel to remove template. Undigested library DNA was purified from agarose gels and transformed into electrocompetent $E$. coli SS320 (Lucigen) and again plated onto LB-TAG agar Bioassay dishes as before. Phage were packaged as described (23) using Deltaphage (52) and precipitated with PEG/ $\mathrm{NaCl}$ twice before R1 of selection.

\section{Phage display selection for affinity maturation}

The selection of the second-generation libraries was performed similarly as described above for the primary

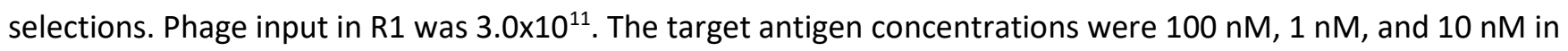
R1 to R3. Washing was increased from $5+5$ in R1 to 10+10 in R2 and R3. In the thermal branch, phage were heated for $15 \mathrm{~min}$ to $60^{\circ} \mathrm{C}$ and $65^{\circ} \mathrm{C}$ in R2 and R3, respectively. After the heat challenge, phage samples were cooled down on ice and centrifuged at 17,000xg/5 min. Phage samples were transferred to new tubes for selection. In the competition branch, bead-bound positively selected phage particles were incubated with $100 \mathrm{nM}$ of scFv or $50 \mathrm{nM}$ of hlgG1 of the respective mother clones. Selected phages were rescued by superinfection with M13K07 for low valence display and Deltaphage for high valence display, respectively.

\section{Screening of affinity matured selection output}

Screening of selection output was done in soluble scFv format as described for screening of the primary selection output. For screening in phage format, single clones from the R3 output were picked into 96-deep-well plates containing $2 \mathrm{x} Y \mathrm{~T}-\mathrm{AG}$ and cultured $\mathrm{ON} / 37^{\circ} \mathrm{C} / 600 \mathrm{rpm} .10 \mu \mathrm{l}$ were transferred to fresh plates containing the same medium and grown for $3 \mathrm{~h} / 37^{\circ} \mathrm{C} / 600 \mathrm{rpm}$. E. coli SS320 were infected with $10^{9} \mathrm{cfu}$ Deltaphage per well and incubated at $37^{\circ} \mathrm{C} / 30 \mathrm{~min}$ with gentle shaking, and $30 \mathrm{~min}$ with vigorous shaking. Cells were pelleted and resuspended in $50 \mu \mathrm{l} 2 x$ YT-AK and phage were packaged ON/30 ${ }^{\circ} \mathrm{C} / 600 \mathrm{rpm}$. Cells were harvested and $100 \mu \mathrm{L}$ supernatant were used for screening in ELISA.

\section{Prokaryotic protein expression}

Selected variable regions were either individually subcloned or batch-cloned as Ncol/Not I fragments from phagemids into the pFKPEN vector (68), that contains a His-tag as well as a Myc-tag. DNA was transformed into electrocompetent E. coli XL1-Blue. For protein expression, the E. coli were inoculated into $10 \mathrm{~mL} 2 \mathrm{x}$ YT-AG and incubated $37 \% \mathrm{ON} / 200 \mathrm{rpm}$. Cultures were reinoculated into $1 \mathrm{~L} 2 \mathrm{x}$ YT-AG to OD600nm 0.025 and grown to 
OD600nm 0.6. Medium was changed to $1 \mathrm{~L} 2 \mathrm{x}$ YT-A supplemented with $0.1 \mathrm{mM} \mathrm{IPTG}$ and incubated $30^{\circ} \mathrm{C} / \mathrm{ON} / 200$ rpm. Cells were pelleted and periplasmic fractions extracted using $80 \mathrm{~mL}$ periplasmic extraction solution as described in screening of primary selection output. Cells were pelleted, and periplasmic fractions were filtered, diluted by adding $100 \mathrm{~mL}$ PBS supplemented with $150 \mathrm{mM} \mathrm{NaCl}$ and $0.05 \%$ sodium azide, and adjusted to $\mathrm{pH} 7.4$ before purification.

\section{Eukaryotic antibody expression}

pMHC-specific hlgG1 antibodies were generated by cloning variable regions as Bsml/BsiWI fragments into $\mathrm{pLNOH} 2$ oriP and $\mathrm{pLNOK}$ oriP genomic expression vectors encoding constant human $\gamma 1$ and constant human $\mathrm{k}$ domains (69). The $\mathrm{mlgG} 2 \mathrm{~b}$ variants were obtained by cloning variable regions together with mouse $\gamma 2 \mathrm{~b}$ or $\mathrm{k} c \mathrm{CDN}$ as Bsml/BamHI fragments (GenScript) into the same vector. For generation of Fab fragments, a BsiWI/BamHI flanked gene fragment (GenScript) encoding $\mathrm{CH} 1$ of hlgG1, the first residues of the hinge (EPKSCD, the E naturally resulting from $\mathrm{CH} 1$-hinge splicing) and a stop codon DNA was cloned into $\mathrm{pLNOH2}$, thereby exchanging the $\mathrm{C}$ region of the full-length antibody. Isotype control antibodies specific for the outer membrane vesicle (OMV) antigen of Neisseria meningitidis was constructed by cloning Bsml/BsiWI fragments (Genscript) encoding the variable regions of the OMV-specific clone 57AE20 (23) into pLNOH2 oriP and pLNOK oriP encoding hlgG1 or mlgG2b. Of note, some of the pMHC-specific and OMV-specific antibodies were generated both with and without mutation of the Fc glycosylation site (N297) which leads to abolished FCR binding of the antibody. Plasmids were transformed into electrocompetent E. coli XL1-Blue and purified. HEK293E cells (ATCC) were transfected at 90\% confluency with equal amounts of light and heavy chain DNA using Lipofectamine 2000 (Invitrogen) (69). Cells were cultured in RPMI supplemented with $10 \%$ fetal calf serum (FCS), $0.1 \mathrm{mg} / \mathrm{ml}$ streptomycin and $100 \mathrm{U} / \mathrm{ml}$ penicillin. Supernatant was harvested every $2-3$ days for 2 weeks and filtered $(0.22 \mu \mathrm{m})$ before purification.

\section{Purification of antibodies and antibody fragments}

Antibodies, Fab fragments, or scFvs were captured on protein L columns (HiTrap, GE Healthcare) or CH1 capture

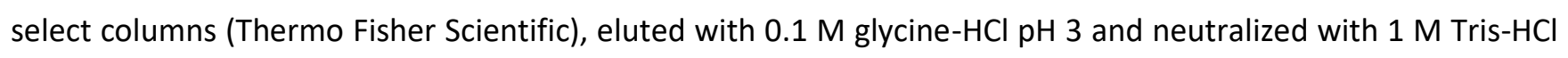
$\mathrm{pH}$ 8. Alternatively, scFvs were purified by IMAC (HiTrap, GE Healthcare) and eluted with $50 \mathrm{mM}$ Tris-HCl, $0.5 \mathrm{M}$ $\mathrm{NaCl} 0.5 \mathrm{M}$ imidazol pH 7.4. Proteins were size excluded on a Superdex 200 column using PBS supplemented with $150 \mathrm{mM} \mathrm{NaCl}$ (GE Healthcare). 
PMHCELISA

EIA/RIA plates were coated with $10 \mu \mathrm{g} / \mathrm{ml}$ NeutrAvidin in PBS (100 $\mu \mathrm{l} /$ well, Thermo Scientific) and incubated ON/4 ${ }^{\circ} \mathrm{C}$. Plates were blocked with $5 \%$ skim milk powder in PBS-T (300 $\mu \mathrm{l} /$ well) for $1 \mathrm{~h} / \mathrm{RT}$ with agitation. Equal amounts of biotinylated pMHC (normalized to $300 \mathrm{ng} / \mathrm{ml}$ ) were captured for $1 \mathrm{~h} / \mathrm{RT}$ and followed by addition of $0.5 \mu \mathrm{g} / \mathrm{ml}$ purified pMHC-specific antibodies, $5 \mu \mathrm{g} / \mathrm{ml}$ purified Fab fragments or purified scFvs, and varying concentrations of soluble scFv or phage during screening. Bound scFv were detected with mouse anti-Myc tag antibody (Invitrogen, 1:5,000) and anti-mouse-HRP (GE Healthcare, 1:2,000). Bound hlgG1 were detected with anti-hlgGALP (Sigma Aldrich, 1:3,000), Fab fragments with anti-hCK-ALP (Sigma, 1:3,000), phage particles with anti-M13HRP (Amersham Biosciences, 1:5,000). All antibodies were diluted in PBS-T. Plates were developed with TMB solution (Calbiochem) and read at $450 \mathrm{~nm}$ using a microplate reader (Tecan sunrise) after the enzymatic reaction had been stopped by addition of $1 \mathrm{M} \mathrm{HCl}$. Alternatively, the plates were developed with $1 \mathrm{mg} / \mathrm{ml}$ phosphatase substrate (Sigma Aldrich) in diethanolamine buffer and read at $405 \mathrm{~nm}$.

\section{Thermostability analysis by nanoDSF}

Melting temperatures were assessed using a Prometheus nanoDSF (NanoTemper). $10 \mu \mathrm{L}$ of $0.2 \mathrm{mg} / \mathrm{mL}$ purified Fab fragments in PBS were transferred to glass capillaries (NanoTemper) in triplicates. A $1^{\circ} \mathrm{C} / \mathrm{min}$ temperature gradient was applied to the samples from $20{ }^{\circ} \mathrm{C}$ to $95^{\circ} \mathrm{C}$. Excitation wavelength was $295 \mathrm{~nm}$ and emission was measured at $330 \mathrm{~nm}$ and $350 \mathrm{~nm}$. Data was collected and analyzed using AB-Protein PR.ThermControl V2.12.

\section{Binding analysis by SPR}

Kinetics of antibody binding to PMHC were determined using a Biacore T200 (GE Healthcare). Briefly, NeutrAvidin $(10 \mu \mathrm{g} / \mathrm{mL}$ in $10 \mathrm{mM}$ sodium acetate, $\mathrm{pH} 4.5)$ was coupled onto a CM3 sensor chip to 1000 response units (RU) by amine coupling. Soluble, recombinant, biotinylated pMHC $(1 \mu \mathrm{g} / \mathrm{mL})$ was then captured at approximately 80 $90 \mathrm{RU}$ by passing over the flow cells at $10 \mu \mathrm{L} / \mathrm{min}$. Antibody samples (scFv or Fab fragments) diluted in PBS supplemented with $0.05 \%(\mathrm{v} / \mathrm{v})$ surfactant P20 were run over the surface at various concentrations using either single cycle kinetics or a multi cycle method. For off-rate ranking, all samples were used at $0.5 \mu \mathrm{M}$. Binding experiments were performed at $25^{\circ} \mathrm{C}$ with a flow-rate of $30 \mu \mathrm{L} / \mathrm{min}$. The surface was regenerated using either glycine- $\mathrm{HCl} \mathrm{pH} 2.2$ or diethylamine $\mathrm{pH} 11$ when necessary. Binding data were buffer subtracted and NeutrAvidinreference-cell subtracted using the T200 Evaluation Software v1.0. Kinetic constants were determined by fitting the data to a 1:1 Langmuir binding model.

B-cell lines 
The murine A20 B-cell lymphoma cell line had previously been engineered to express HLA-DQ2.5 with different peptide variants covalently linked to the $\operatorname{MHC} \beta$-chain $(9,21)$. Notably, the ectodomains are identical as in the soluble pMHC molecules used for selection, screening and characterization of antibody binding by SPR and ELISA. The human B-cell lymphoma Raji cells express HLA-DQ2.5. The human EBV-transduced B-cell line VAVY is homozygous for HLA-DQ2.5, while MOU and BM92 are homozygous for HLA-DQ2.2 and HLA-DQ8, respectively. All cells were cultured under standard conditions in RPMI 1650 supplemented with 10\% FCS, $0.1 \mathrm{mg} / \mathrm{ml}$ Streptomycin and $100 \mathrm{U} / \mathrm{ml}$ Penicillin.

\section{Flow cytometric analyses of stained B cells}

Raji and EBV-B cells were loaded with peptide by culturing in presence of $50 \mu \mathrm{M}$ peptide ON. The following peptides were used (9mer core epitope sequences are underlined): 33mer $\alpha$-gliadin LQLQPFPQPELPYPQPELPYPQPELPYPQPQPF, 12mer DQ2.5-glia- $\alpha 1$ a QLQPFPQPELPY and either an 11mer DQ2.5glia- $\alpha 2$ PQPELPYPQPE or 12mer DQ2.5-glia- $\alpha 2$ PQPELPYPQPQL. The cell lines were stained with pMHC-specific $\mathrm{mlgG} 2 \mathrm{~b}$ antibodies $(5 \mu \mathrm{g} / \mathrm{ml}$ ) directly conjugated to PE (Abcam) in the presence of human FcR blocking reagent (Miltenyi, 1:50). For staining of A20 B cells, 3.C11 hlgG1 antibody was used at $5 \mu \mathrm{g} / \mathrm{mL}$ together with rat antimouse CD16/CD32 block (BD, 1:200). Bound hlgG1 were detected with biotinylated goat $F\left(a b^{\prime}\right) 2$ anti-human IgG (Southern Biotech, $2 \mu \mathrm{g} / \mathrm{mL}$ ) followed by streptavidin R-PE (Invitrogen, $2 \mu \mathrm{g} / \mathrm{mL}$ ). Alternatively, A20 cells were stained with biotinylated 2.12.E11 $\mathrm{mlgG} 1(5 \mu \mathrm{g} / \mathrm{ml})$ followed by streptavidin R-PE as before. All stainings were performed on ice using V-bottom shaped 96-well plates and an equal number of cells were used in each staining (at least 100,000). PBS supplemented with $2 \%$ FCS was used to wash cells and for dilution of antibodies and streptavidin. Data was acquired using an Attune NxT flow cytometer (Thermo Fisher Scientific). For the alanine scan experiments, Raji B cells were loaded with the 12mer DQ2.5-glia- $\alpha 2$ YPQPELPYPQPE (wt) or single alanine substitutions. The loaded cells were stained with $5 \mu \mathrm{g} / \mathrm{ml}$ pMHC-specific hlgG1 in presence of human FcR blocking reagent (Miltenyi, 1:100), followed by goat F(ab')2-anti human IgG-biotin (Southern Biotech, $2 \mu \mathrm{g} / \mathrm{ml}$ ) and Streptavidin-PE (ThermoFisher $2 \mu \mathrm{g} / \mathrm{ml}$ ). Cells were washed, resuspended in autoMACS buffer with $2 \%$ FCS and data acquired on an Accuri C6 flow cytometer. Data analysis was performed using FlowJo software (Tree Star).

\section{Human material}

Research protocols and use of human duodenal biopsy material have been approved by the Regional Ethics Committee of South-Eastern Norway (REK Sør- $\varnothing$ st approval ID 6544). All subjects gave informed written consent to donate biological material to a REK Sør- $\varnothing$ st approved biobank (ID 20521). CeD diagnosis was based on the guidelines from the British Society for Gastroenterology including clinical history, anti-TG2 serological testing, 
HLA typing and histological analysis of small intestinal biopsies obtained by esophagogastroduodenoscopy and forceps sampling from the duodenum (70). Small intestinal resections (duodenum-proximal jejunum tissue) were obtained from non-pathological small intestine during Whipple procedure (pancreatoduodenectomy) of pancreatic cancer patients who also donated material to the biobank (number 2012/341) and gave informed, written consent. Normal histology of the duodenal mucosa was confirmed in these samples.

Isolation of single-cell suspensions from duodenal biopsies and small intestinal resections and flow cytometry Single-cell suspensions from duodenal biopsies or small intestinal resection were prepared as described (71) and blocked with FcR Blocking Reagent (Miltenyi Biotec) and stained with the following antibodies specific for CD markers; CD3-FITC (OKT3, Biolegend), CD11c-APC (S-HCl-3, BD Biosciences), CD14-APC (HCD14, Biolegend), CD19-PE-Cy7 (HIB19, Biolegend), CD27-BV421 (O232, Biolegend), CD38-APC-Cy7 (HIT2, Biolegend) and CD45BV510 (H130, Biolegend), all at 1:20. Alternatively, CD3-Pacific Blue (OKT3, Biolegend), CD11C-APC (S-HCl-3, BD Biosciences), CD14-APC (HCD14, Biolegend), CD19-PerCP-Cy5.5 (HIB19, Biolegend), CD27-Pe-Cy7 (LG-7F9, Biolegend), CD38-APC-Cy7 (HIT2, Biolegend) and CD45-BV510 (H130, Biolegend), all at 1.5:50 were used. Peptide presentation was analyzed using mlgG2b 107, mlgG2b 3.C11 or mlgG2b OMV (all in-house generated, $10 \mu \mathrm{g} / \mathrm{ml}$ ), followed by detection using anti-mlgG2b conjugated to PE (Biolegend, $1 \mu \mathrm{g} / \mathrm{ml}$ ). Propidium iodide or LIVE/DEAD Fixable Violet Dead Cell Stain (Invitrogen) were used for exclusion of dead cells and samples were immediately acquired on LSR Fortessa cytometer (BD Biosciences). Data analysis was performed using FlowJo software (Tree Star).

Retroviral transduction of human SKW3 T cells and K562 cells, and flow cytometry TCR sequences encoding the variable domains of TCRs 380 (21), 364 (30), S16 (27), and R12C9 (72) were reconstructed by gene synthesis as human/mouse chimeric TCRs as described (21) and cloned into pMSCV (Clontech Laboratories). Retroviral transduction of the SKW3 human T cells (CLS Cell Lines Service GmbH) was performed using the Retro-X Universal Packaging System (Clontech) according to the manufacturer's instructions. Stable, homogenous TCR-expressing SKW3 T cells were obtained by standard cell expansion and FACS sorting using a FACSAria II cytometer (BD Biosciences) based on their TCR expression levels assessed by H57-Alexa647 (Thermo Fisher Scientific) antibody staining. The TCR transduced SKW3 cells were validated for peptide-specific activation using a panel of known agonistic and antagonistic peptides, essentially as described (21). T-cell activation was measured by CD69 up-regulation assessed by anti-human CD69-APC (BD Biosciences) antibody staining. Data was acquired on a BD Accuri C6 cytometer (BD Biosciences) and analyzed using FlowJo software V10 (Tree Star). The human myeloid leukemia cell line K562 (ATCC-CCL-243) was transduced with the 
hCIITA::eGFP dual ORF encoding retroviral vector pMMLV (VectorBuilder GmbH) to induce endogenous HLA class II expression. Stable, homogenous HLA class II positive cells were obtained by standard cell expansion and FACS sorting using a FACSAria II cytometer (BD Biosciences) based on their dual eGFP and HLA expression levels assessed by pan-HLA class II (clone CR3/43-Alexa647) antibody staining.

\section{T-cell activation and inhibition assays}

For T-cell activation assays 50,000 Raji B cells were incubated in RPMI/10\% FCS at $37^{\circ} \mathrm{C} / \mathrm{ON}$ with titrated amounts of peptide, followed by washing to remove remaining free peptide and addition of 40,000 SKW3 T cells. Cells were cultured at $37^{\circ} \mathrm{C} / \mathrm{ON}$ before they were analyzed in flow cytometry. The following peptides were used (9mer core epitopes are underlined): DQ2.5-glia- $\alpha 1 \mathrm{a}$ (QLQPFPQPELPY), and DQ2.5-glia- $\alpha 2$ (PQPELPYPQPE). For alanine scan experiments, Raji B cells were loaded with $5 \mu \mathrm{M}$ of the $12 \mathrm{mer}$ DQ2.5-glia- $\alpha 2$ YPQPELPYPQPE (wt) or single alanine substitutions. As a control, Cell Stimulation Cocktail containing PMA and ionomycin (eBioscience, 1:500) was added to wells containing SKW3 T cells only. Based on the established dose-response in T-cell activation, a peptide concentration estimated to result in about 60\% T-cell activation (measured as CD69 upregulation on the $\mathrm{CD} 19^{\text {neg }}$ population) was chosen for the inhibitory assays. Following $\mathrm{ON}$ incubation with peptide as above and washing, $1 \mu \mathrm{M}$ (final concentration) of either 3.C11 or an isotype control were added to the Raji cells, before T cells were added and incubation continued ON. The resulting T-cell activation was measured as above. As control Abs, either $0.1 \mu \mathrm{M}$ (final concentration) of pan-anti-DR (clone L243: Thermo Scientific) or pan-anti-DQ (clone SPV-L3: Diatech) were added in parallel. As an alternative readout, IL-2 secretion in supernatants was assayed in ELISA using the Human IL-2 ELISA MAX Deluxe Set (Biolegend) according to the manufacturer's protocol.

The TCCs reactive to the DQ2.5-glia- $\alpha 2$ epitope were established from intestinal biopsies of CeD patients (CD412, CD436 and CD820) and have been described before. Briefly, TCC820.250 was generated by direct cloning from intestinal biopsies (73), while TCC412.5.28, TCC436.5.3 and TCC436.5.6 were generated by limiting dilution of a T-cell line established from antigen-challenged intestinal biopsy specimens (12, 30, 74). For T-cell activation assays Raji B cells in RPMI supplemented with 10\% heat-inactivated, pooled human serum, $0.1 \mathrm{mM} 2$ 2Mercaptoethanol, and antibiotics were irradiated with $75 \mathrm{~Gy}$ before 75,000 cells/well were incubated overnight with titrated amounts of peptide at $37^{\circ} \mathrm{C}$. The plates were centrifuged to remove remaining free peptide before addition of 50,000 T cells. 3H-thymidine ( $1 \mu \mathrm{Ci} /$ well) was added 2 days after addition of $\mathrm{T}$ cells and cells were harvested after an additional 16-20 hours using an automated harvester. 3H-thymidine incorporation was measured by liquid scintillation counting. For T-cell inhibition experiments, Raji B cells were incubated overnight with $10 \mu \mathrm{M}$ DQ2.5-glia- $\alpha 2$ (PQPELPYPQPE) or $1 \mu \mathrm{M} 33$ mer (final concentrations) before medium exchange and addition of titrated amounts of mAbs (from $1 \mu \mathrm{M}$ for mAbs 3.C11 and the isotype control and from $0.1 \mu \mathrm{M}$ for 
mAbs SPV-L3 (pan-HLA-DQ, Diatech) and the pan-DR antibody B8-11 (Diatech). Alternatively, T-cell activation was determined by measuring IFN- $\gamma$ secretion by ELISA using supernatants harvested prior to $3 \mathrm{H}$-thymidine pulsing. In brief, plates were coated ON/4 ${ }^{\circ} \mathrm{C}$ with $100 \mu \mathrm{l} 2 \mu \mathrm{g} / \mathrm{ml}$ anti-human IFN- $\gamma$ antibody in 1x PBS (clone 1D1K, MabTech) followed by blocking using 1\% BSA in PBS-T (250 $\mu \mathrm{l} /$ well) for $1 \mathrm{~h} / \mathrm{RT}$ with agitation. Supernatants were diluted in PBS-T (amount varying for the different TCCs) and incubated for 2 h/RT. Captured IFN- $\gamma$ was detected by addition of $1 \mathrm{\mu g} / \mathrm{ml}$ biotinylated 7-B6-1 (MabTech) followed by AP-conjugated Streptavidin (Southern Biotech, 1:2500), both diluted in PBS-T. Plates were developed using $1 \mathrm{mg} / \mathrm{ml}$ phosphatase substrate (Sigma Aldrich) in diethanolamine buffer and read at $405 \mathrm{~nm}$.

Mice

All mice were on C57BI/6 background. HLA-DQ2.5 KI mice express a chimeric MHC class II protein where the peptide-binding extracellular domains of $H 2-A a$ and $H 2-A b 1$ have been replaced with those of $H L A-D Q A 1 * 05: 01$ and HLA-DQB1*02:01 (Dewan et al., manuscript submitted). When homozygous, these mice do not express endogenous $\mathrm{MHC}$ class II molecules since $\mathrm{C} 57 \mathrm{BI} / 6$ lack expression of $\mathrm{H} 2$-IE due to a deletion of the $\mathrm{H} 2$-Ea gene (75). TCR tg mice expressing the rearranged TCR $\alpha$ and TCR $\beta$ chains of T-cell clone 364.1.014 specific for the DQ2.5-glia- $\alpha 2$ epitope were previously described (35). TCR-glia- $\alpha 2$ tg were crossed to CD45.1 mice (B6.SJL-Ptprc ${ }^{a}$ $\mathrm{Pepc}^{\mathrm{b}}$ /BoyCrl; Charles River Laboratories, Calco, Italy) and HLA-DQ2.5 KI mice and bred to homozygosity for HLADQ2.5. Mice were maintained on a gluten free chow (RDI OpenStandard Diet, Research Diets) and bred at the Department of Comparative Medicine, Oslo University Hospital, Rikshospitalet (Oslo, Norway) under specific pathogen free (SPF) conditions. The experiments were approved by the Norwegian Food Safely Authority (Mattilsynet).

In vivo T-cell proliferation assay

Single cell suspensions from spleens and lymph nodes were prepared by carefully grinding and filtering tissues through a $70 \mu \mathrm{m}$ nylon mesh (BD Biosciences) or using the gentleMacs Dissociator (Miltenyi Biotec). Erythrocytes were removed from spleen samples using ammonium-chloride potassium (ACK) lysis buffer. CD4 ${ }^{+} \mathrm{T}$ cells were isolated from spleens and lymph nodes of HLA-DQ2.5 TCR-glia- $\alpha 2$ double tg mice by negative selection using the EasySep Mouse $\mathrm{CD}^{+} \mathrm{T}$ cell isolation kit (StemCell Technologies). The purity of $\mathrm{CD}^{+}$population was $>90 \%$. Isolated $\mathrm{CD}^{+} \mathrm{T}$ cells were labeled with Cell Trace Violet (CTV) (Molecular Probes) and approximately $2.5 \times 10^{6}$ cells were adoptively transferred to homozygous HLA-DQ2.5 KI recipient mice by intravenous injection. The following day, recipient mice were administered intraperitoneally with $200 \mu \mathrm{g}$ of either of the mAbs $3 . \mathrm{C} 11$ (mlgG2b), anti-OMV (mlgG2b) or anti-HLA-DQ (SPV-L3, mlgG2a) in $200 \mu$ PBS or PBS alone. 30 minutes after 
antibody administration, mice received $100 \mu \mathrm{g}$ deamidated 33mer (LQLQPFPQPELPYPQPELPYPQPELPYPQPQPF) in $200 \mu \mathrm{l}$ PBS by intragastric gavage. Peyer's patches, gut-draining mesenteric lymph nodes (MLN), non-draining inguinal lymph nodes (ILN) and the spleen were isolated $48 \mathrm{~h}$ after peptide antigen administration and analyzed for T-cell proliferation.

\section{Flow cytometry}

Cells were resuspended in PBS containing 2\% FCS (v/v), pretreated with anti-CD16/32 (93; BioLegend) and then stained with optimal amounts of FITC-conjugated anti-CD45.1, PercpCy5.5-conjugated anti-CD4 and PEconjugated anti-CD3 (all Biolegend). Cells were analyzed on FACSCalibur (BD Biosciences) or Attune NxT Flow Cytometer (Thermo Fisher Scientific). Data analysis was performed using FlowJo software (Tree Star). 


\section{Supplementary Information}
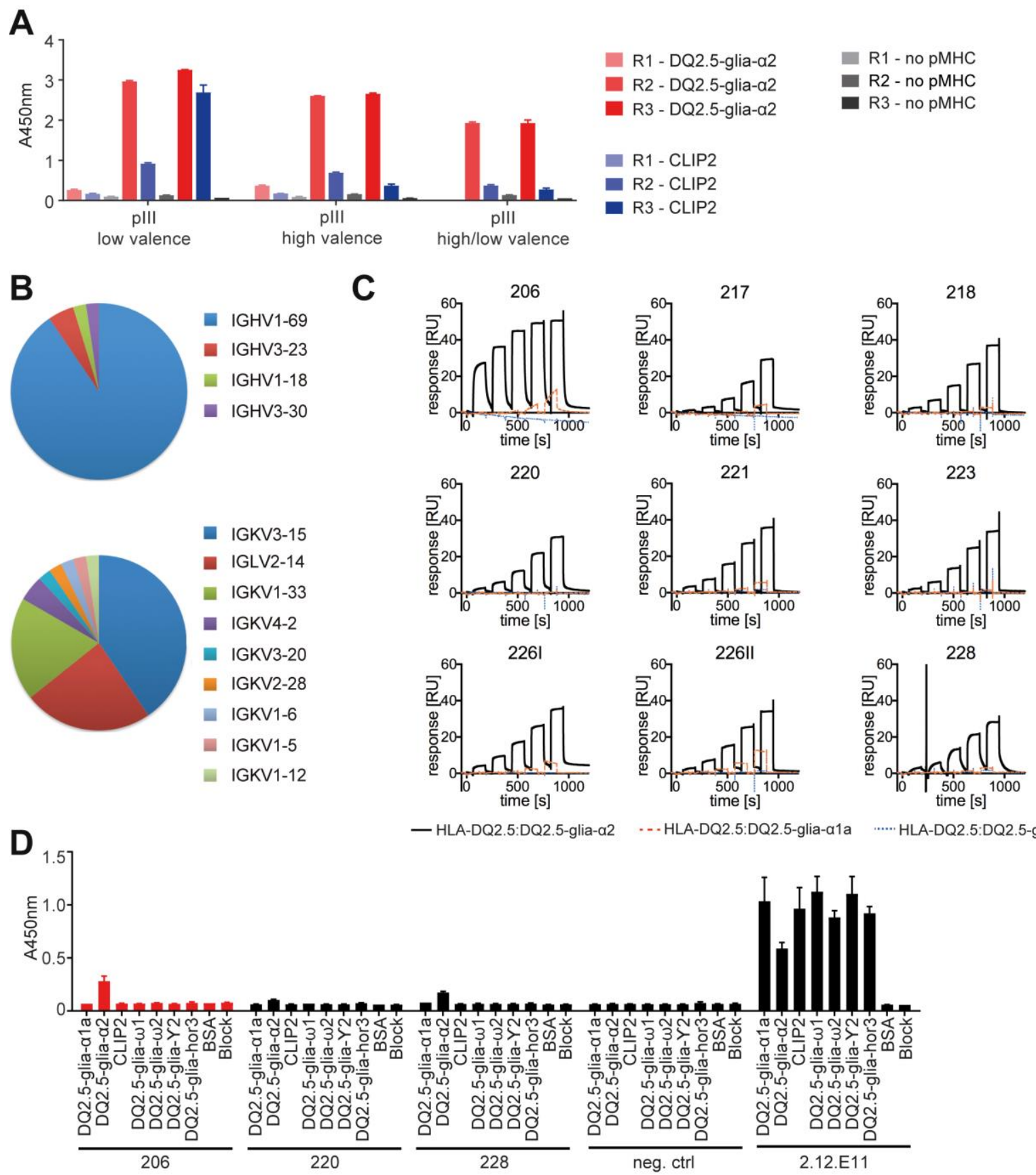

Figure S1. Primary selection against HLA-DQ2.5:DQ2.5-glia-a2. (A) Polyclonal phage ELISA to assess the antigen reactivity of the phage outputs after R1-R3. HLA-DQ2.5:CLIP2, which was used for negative selection, and block was used to monitor HLA-DQ2.5 binding irrespective of peptide and background, respectively. (B) 42 sequences of positive clones were identified after three rounds of selection and V gene usage was analyzed using IMGT/V-quest. (C) Single scFv clones were produced in E. coli, affinity purified, size excluded, and analyzed in by SPR as indicated. (D) Lead candidates 206, 220, and 228 were expressed as hlgG1 in HEK293E cells, purified on protein L columns and size excluded and then tested in ELISA for binding to different peptide MHC complexes. Functional pMHC was normalized using pan-HLA-DQ2 antibody 2.12.E11. 
A

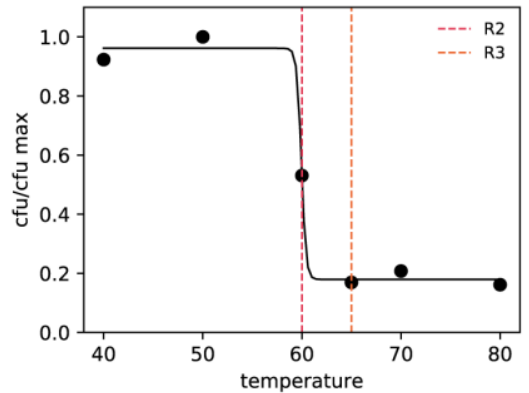

B

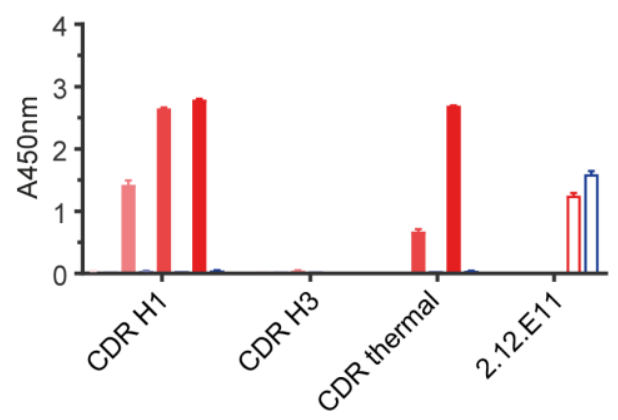

R0 - DQ2.5-glia- $\alpha 2$

R1 - DQ2.5-glia-a2

R2 - DQ2.5-glia- $\alpha 2$

R3 - DQ2.5-glia- $\alpha 2$

- R0 - CLIP2

R1 - CLIP2

R2 - CLIP2

R3 - CLIP2
C

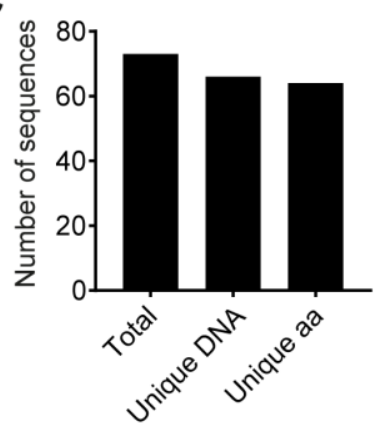

D

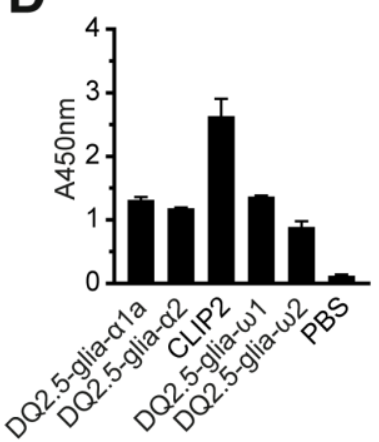

Figure S2. Selection for high affinity antibodies. (A) The first-generation antibody 206 was displayed at HV on phage coat protein pIX and heated at different temperatures for 10 min as annotated. The sample was cooled down and assessed for residual binding to protein $L$ in ELISA and infectious titration of bound particles. We estimated a melting temperature by fitting a sigmoid function to the data (black line) and obtained a melting temperature of $60{ }^{\circ} \mathrm{C}$. Heat challenge temperatures for rounds 2 and 3 of selection are indicated for comparison (red and orange dotted lines). (B) After three rounds of selection, a polyclonal ELISA was performed to assess enrichment of binders against HLA-DQ2.5:DQ2.5-glia- $\alpha 2$. (C) Positive clones were sequenced and numbers of unique DNA and amino acid sequences are represented as bars. (D) Presence of functional pMHC molecules was verified by detection with the HLA-DQ2-specific antibody 2.12.E11 in ELISA. 

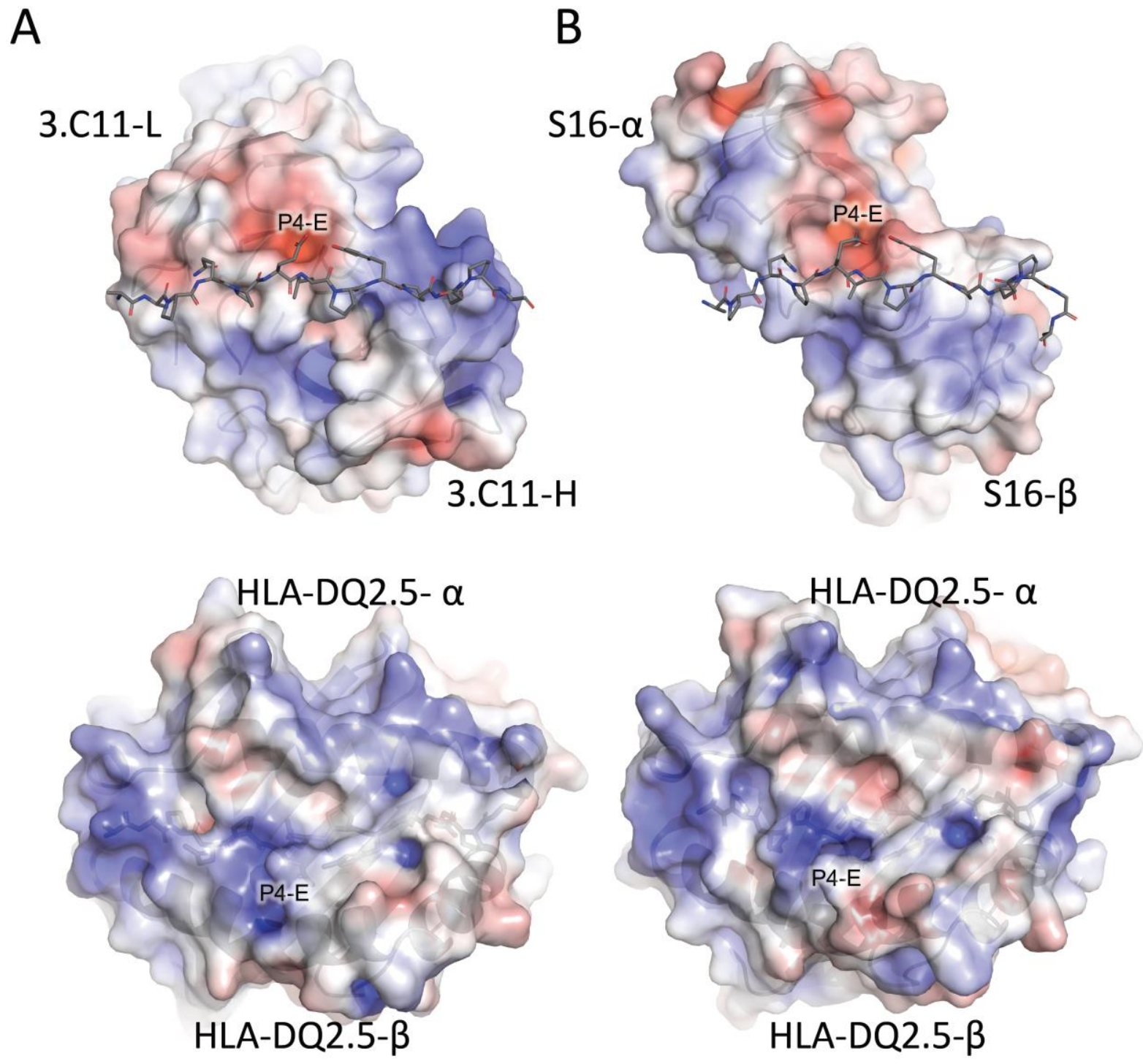

\section{$-5 \mathrm{kT} / \mathrm{e}$}

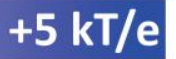

Figure S3. Electrostatic surface potential of Fab 3.C11 and TCR S16 with pMHC. (A) Electrostatic surface potential of the 3.C11 - HLADQ2.5:DQ2.5-glia- $\alpha 2$ complex, and (B) the S16 - HLA-DQ2.5:DQ2.5-glia- $\alpha 2$ complex. Surface potentials were calculated with the APBS plugin for Pymol. 

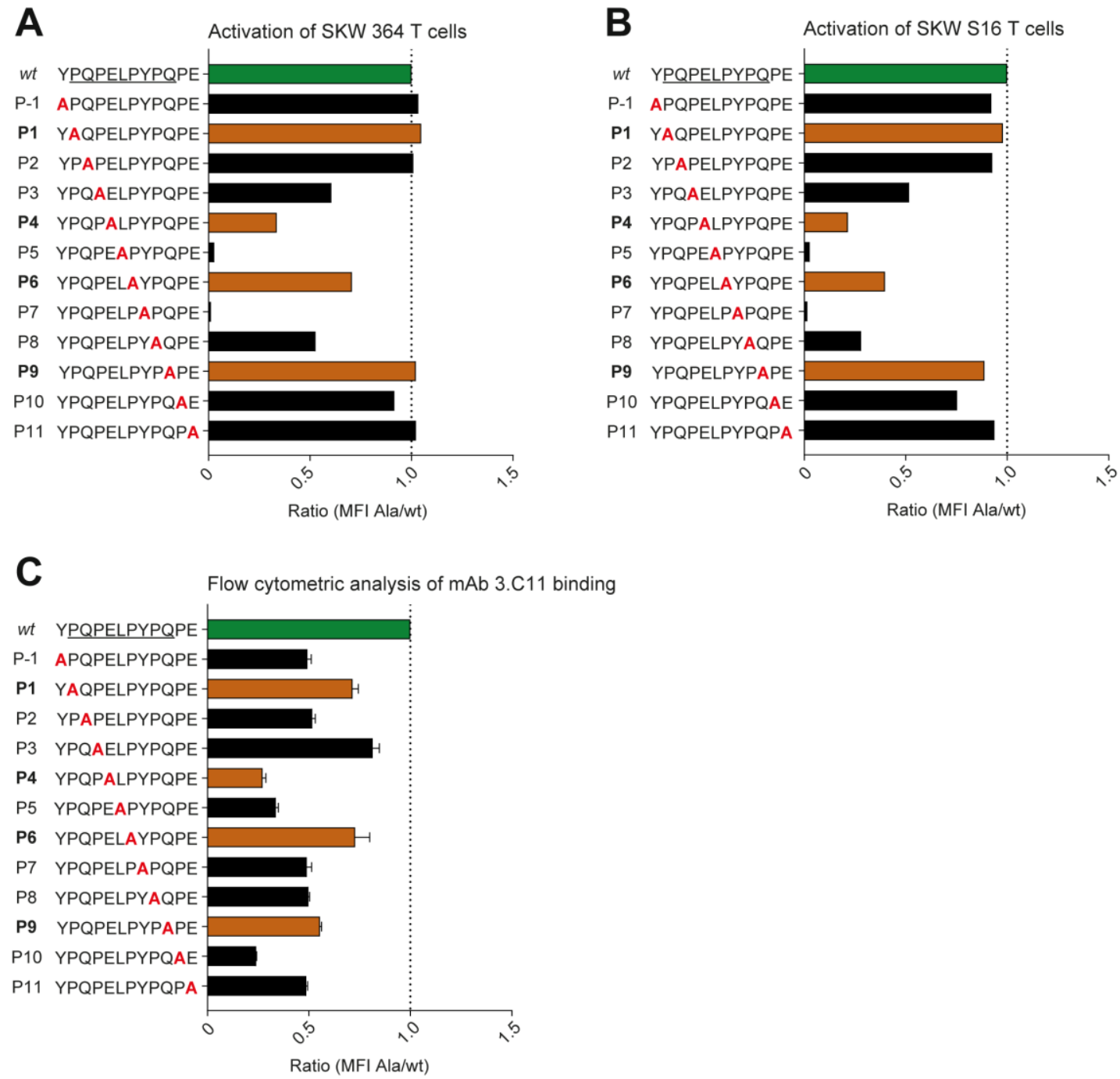

Figure S4. DQ2.5-glia- $\alpha 2$ peptide reactivity pattern of HLA-DQ2.5:DQ2.5-glia- $\alpha 2$-specific $T$ cells and mAb 3.C11. (A and B) Responsiveness of SKW 364 (A) and SKW S16 (B) T cells to Raji B cells loaded with single alanine substitution variants of the DQ2.5-glia- $\alpha 2$ peptide. T-cell responses were measured as $\mathrm{CD}^{+} 9^{+} \mathrm{CD} 19^{-}$cells in flow cytometry. The 9mer core of the wt DQ2.5-glia- $\alpha 2$ peptide is underlined; the response to the wt peptide in defined as 1 and the bar is green; position of anchor residues is indicated in bold and bars in brown; the $\mathrm{E}$ at $\mathrm{p} 4$ of the wt peptide is introduced by deamidation. (C) Flow cytometric analysis of mAb $3 . C 11$ binding to Raji B cells loaded with the DQ2.5-glia- $\alpha 2$ peptide variants. 

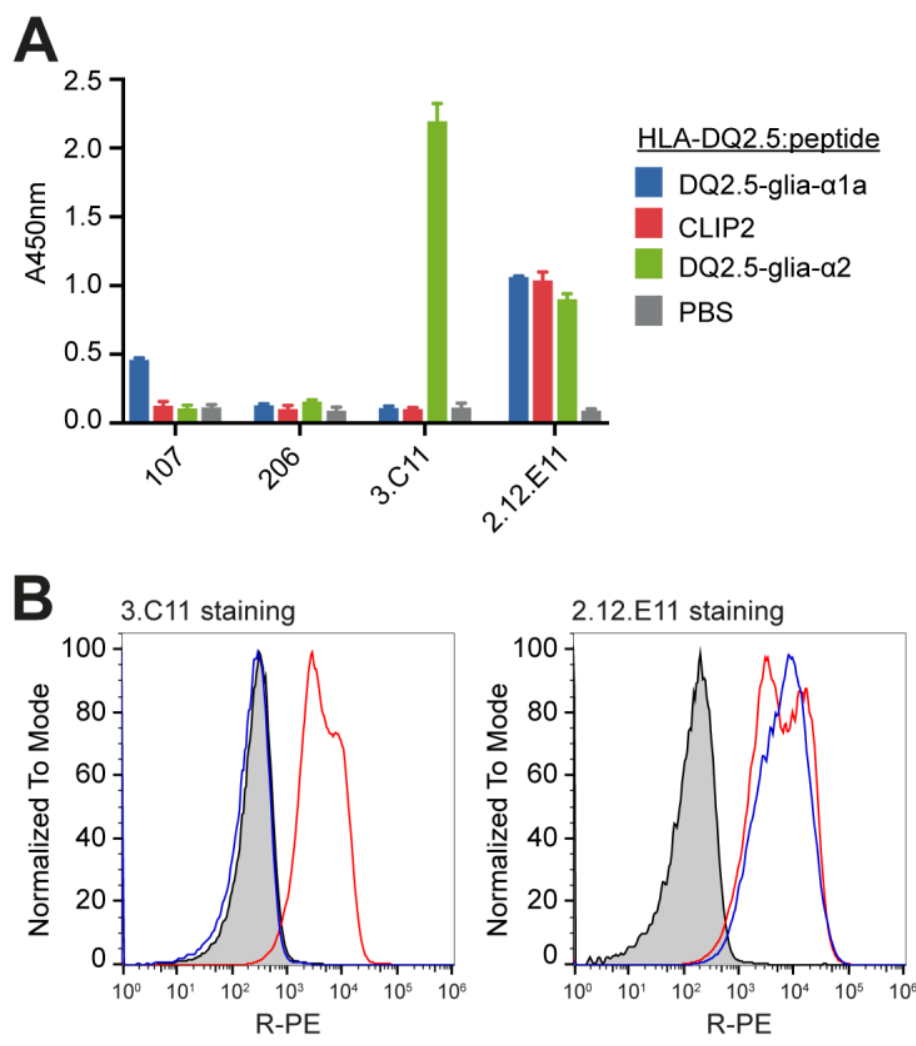

A20 HLA-DQ2.5:peptide

— DQ2.5-glia- $\alpha 2$

- CLIP2

— Isotype ctrl. mAb on DQ2.5-glia- $\alpha 2$ cells

C

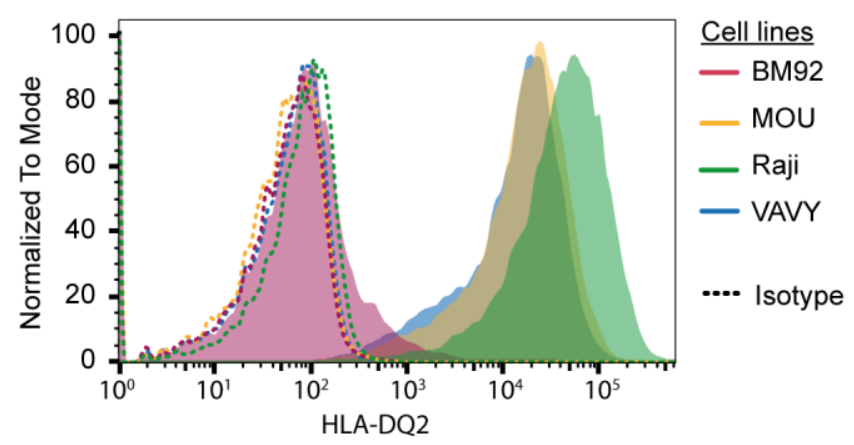

Figure S5. Staining for HLA-DQ2 expression and detection of cell surface pMHC using antibody 3.C11. (A) The antibodies were expressed as mlgG2b antibodies and analyzed in ELISA for binding to soluble recombinant pMHC molecules as before $(0.5 \mathrm{\mu g} / \mathrm{mL}$ pMHC specific antibodies). The HLA-DQ2 antibody 2.12.E11 was used to control for pMHC immobilization levels. (B) Murine A20 B cells engineered to express HLA-DQ2.5 with covalently linked peptide were stained with $5 \mu \mathrm{g} / \mathrm{ml} 3 . \mathrm{C} 11$ hlgG1 or $5 \mu \mathrm{g} / \mathrm{mL}$ 2.12.E11 mlgG1 or isotype controls. (C) Raji lymphoma B cells and VAVY, MOU, and BM92 EBV EBV-B cells were stained with $5 \mu \mathrm{g} / \mathrm{mL}$ 2.12.E11 directly conjugated to R-PE (filled histograms) or an isotype control (dotted lines). 

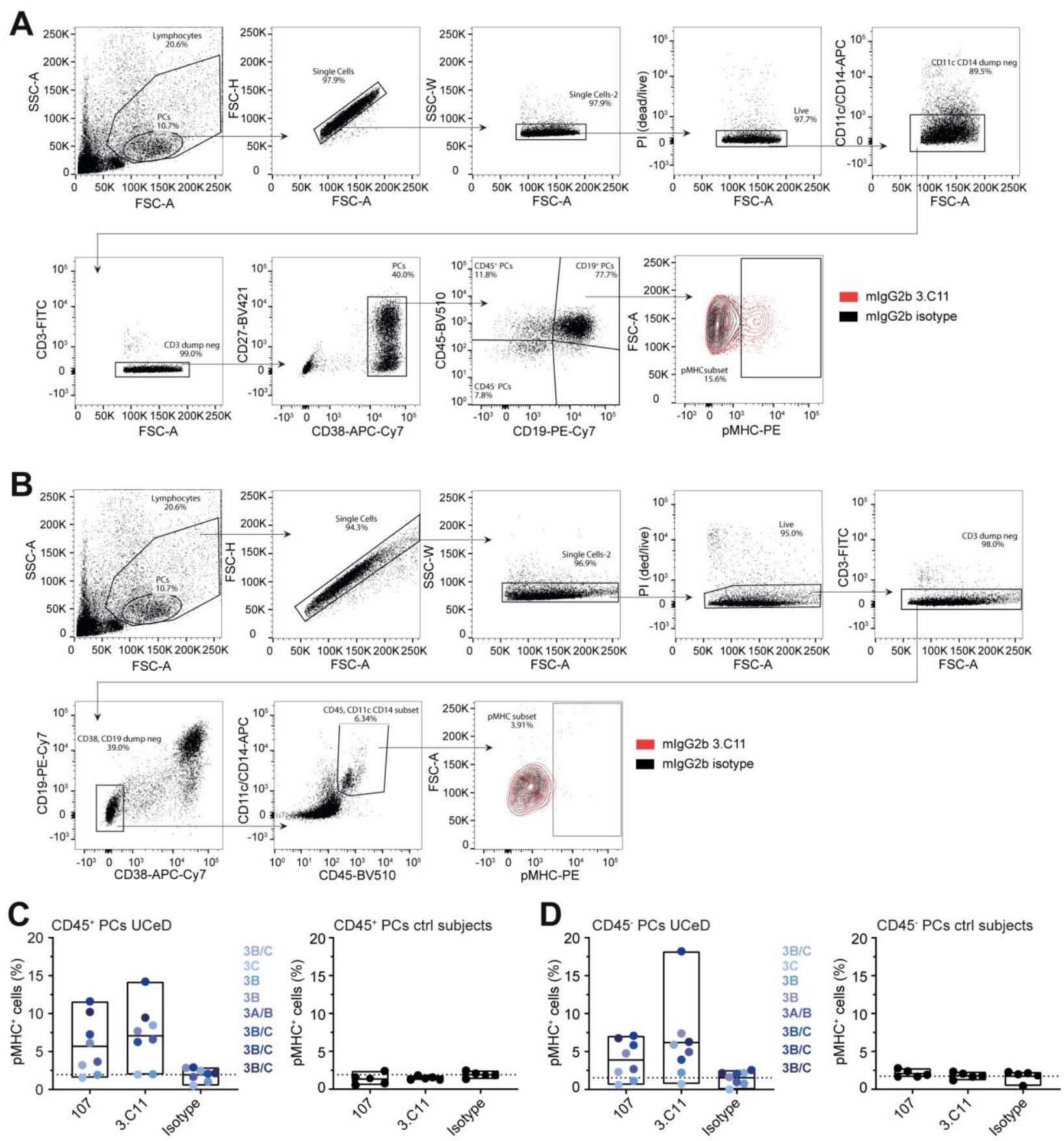

Figure S6. The pMHC-specific antibodies detect gluten peptide presentation on PC subsets in CeD small intestinal biopsies. Single-cell suspensions were prepared from either untreated HLA-DQ2.5 $\mathrm{CeD}$ patients or controls with a healthy mucosal histology. Bound 107 or $3 . C 11 \mathrm{mlgG} 2 \mathrm{~b}$ or an isotype control was detected with a PE-conjugated secondary antibody. (A and B) Representative gating strategy for analysis of peptide presentation on (A) PCs and (B) DCs/Mfs. PCs were gated as live, large lymphocytes, $\mathrm{CD}^{-} \mathrm{CD} 11 \mathrm{c}^{-} \mathrm{CD} 14^{-} \mathrm{CD} 38^{+} \mathrm{CD} 27^{+/}$cells and separated into different subsets based on $\mathrm{CD} 19$ and $\mathrm{CD} 45$ expression. DCs/Mfs were gated as live, $\mathrm{CD}^{-} \mathrm{CD} 19^{-} \mathrm{CD} 27^{-} \mathrm{CD} 38^{-} \mathrm{CD} 11 \mathrm{c}^{+} \mathrm{CD} 14^{+}$cells. The frequency of $\mathrm{pMHC} \mathrm{C}^{+}$cells was assessed using 107 and 3.11 and compared to use of an isotype control antibody (isotype). (C and D) The fraction of pMHC ${ }^{+}$cells among (C) CD45 ${ }^{+}$PCs and (D) CD45 PCs in untreated CeD patients $(n=8, U C e D)$ and controls $(n=5$, two of the controls were HLA$\left.\mathrm{DQ} 2.5^{+}\right)$. Dotted lines represent background staining using the isotype control. 

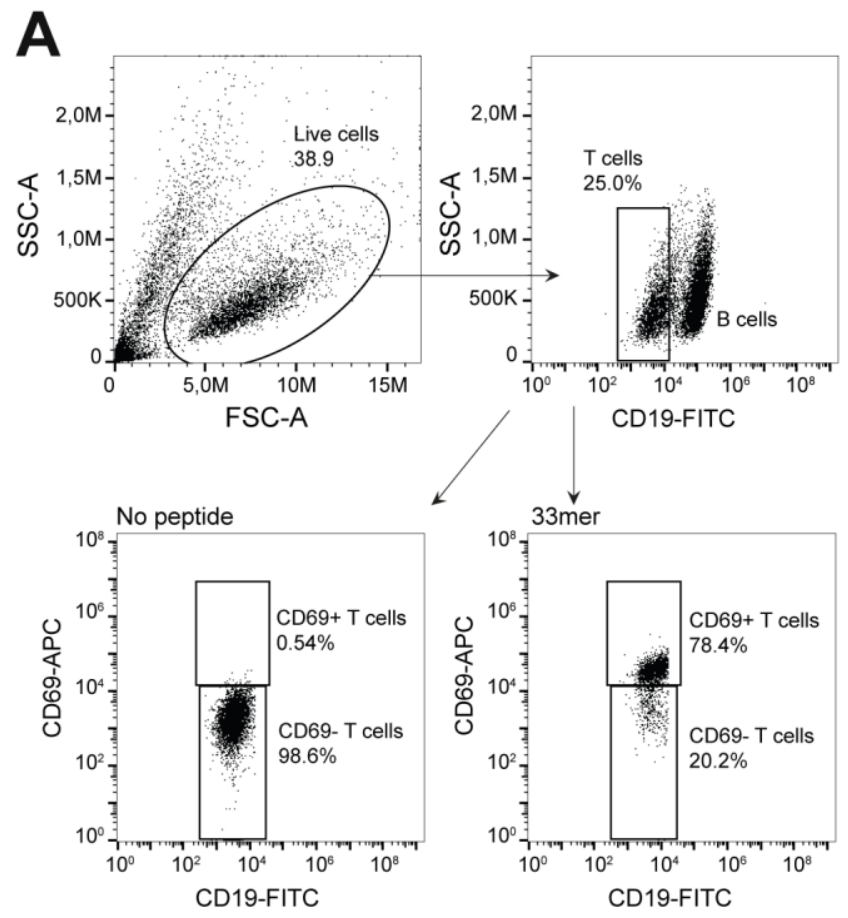
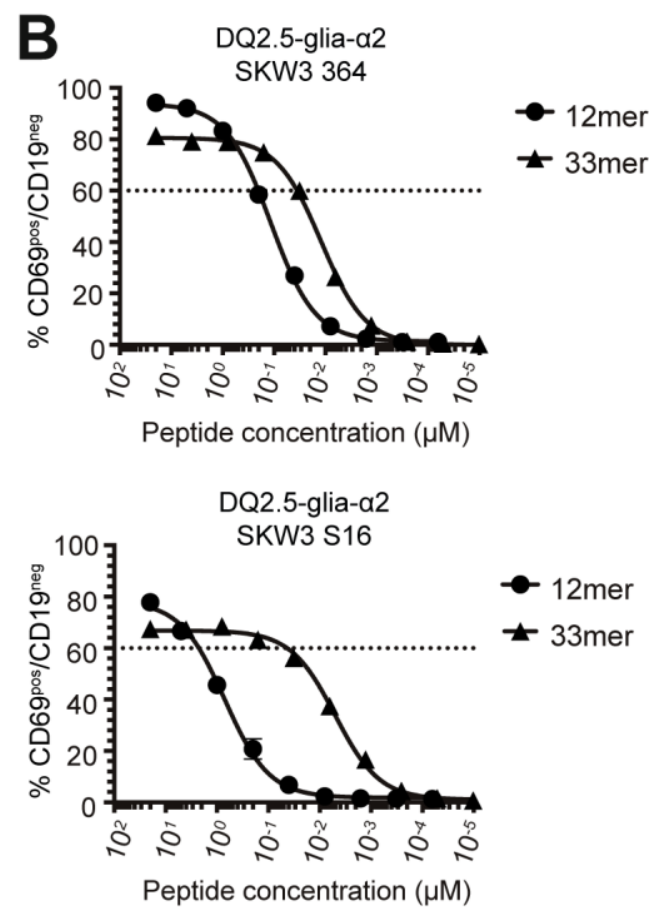
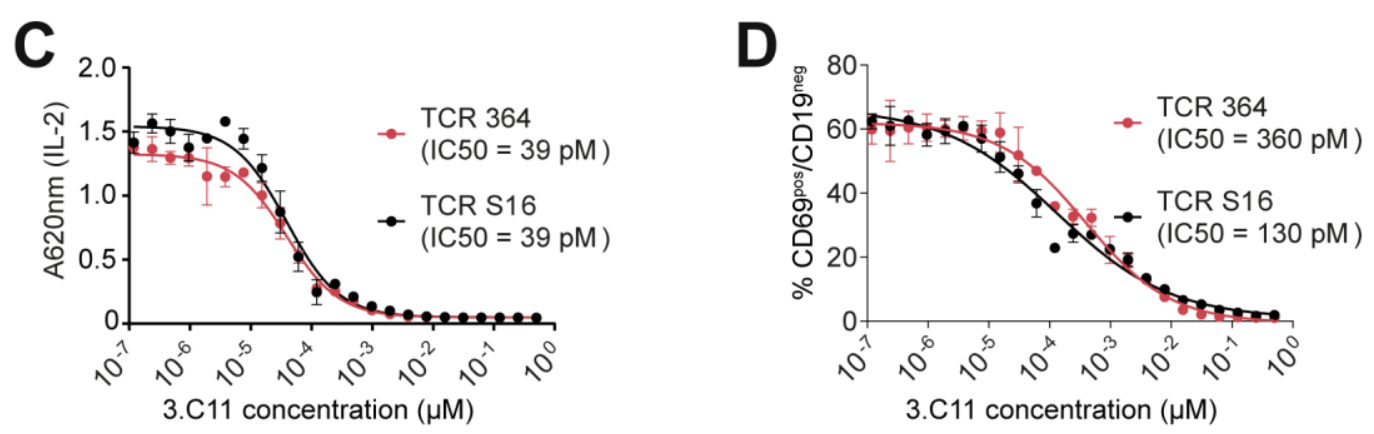

Figure S7. Activation of gluten-specific SKW3 T cells. (A and B) Raji B cells were loaded with a serial dilution of peptide and co-cultured with engineered gliadin-specific SKW3 T cells. T-cell activation was measured as $\mathrm{CD}^{-} 9^{+} \mathrm{CD} 19^{-}$cells in flow cytometry. (A) Flow cytometric gating strategy. Live cells were gated based on FSC and SSC and T cells are separated from Raji $B$ cells as CD19 negative cells. Percent $C D 69^{+} T$ cells were determined based on gates set on T cells co-cultured with nonloaded Raji B cells (no peptide). (B) Representative peptide titration. Error bars illustrate mean \pm SD of duplicates $(n=2)$. The dotted line indicates 60\% T-cell activation. (C and D) Titrated amounts of 3.C11 were added to 33-mer peptide-loaded Raji $B$ cells prior to incubation with SKW T cells. T-cell activation was assessed by IL-2 secretion in ELISA (C, $n=1)$ or by CD69 upregulation in flow cytometry $(D, n=1)$. Error bars illustrate mean \pm SD of duplicates. IC50 values were determined from four-parameter dose response curves using GraphPad prism v9. 

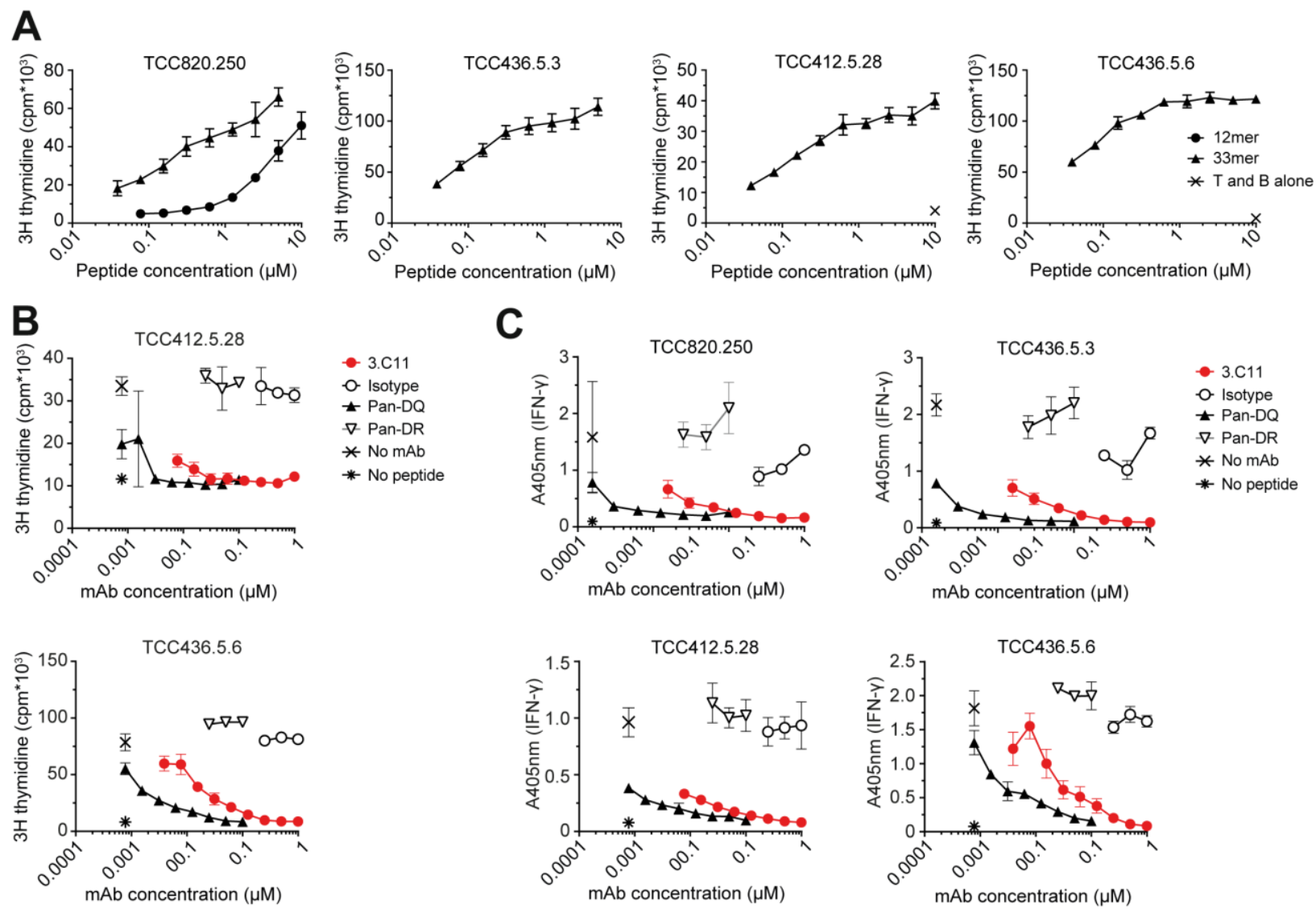

Figure S8. Inhibition of gluten-specific TCCs. (A) DQ2.5-glia- $\alpha 2$-reactive primary TCCs were co-cultured with Raji B cells preloaded with serial dilutions of peptide. T-cell proliferation was determined by incorporation of thymidine. Error bars illustrate mean \pm SD of triplicates $(n=1)$. (B and C) HLA-DQ2.5:DQ2.5-glia- $\alpha 2$-specific TCCs were co-cultured with 33merloaded Raji B cells in presence of titrated amounts of antibodies as annotated. Pan-HLA-DQ antibody (SPV-L3), pan-HLA-DR antibody (B8.11) and an isotype were included as controls. T-cell activation was assessed by (B) measuring thymidine incorporation by proliferating cells $(n=2)$ or $(C)$ by measuring IFN $-\gamma$ secretion in ELISA $(n=2 / 3)$. Error bars represent mean \pm SD of triplicates. 
Supplementary Table 1. Gene segment usage among the HLA-DQ2.5:DQ2.5-glia- $\alpha 1 a-s p e c i f i c(9)$ and the HLADQ2.5:DQ2.5-glia- $\alpha 2$-specific clones (8 lead candidates from the first generation).

\begin{tabular}{llllll}
\hline Clone & IGHV & IGHD & IGHJ & IGKV & IGKJ \\
\hline 101 & $6-1 * 01$ & $6-19 * 01$ & $6 * 02$ & $1-9 * 01$ & $4 * 01$ \\
106 & $6-1 * 01$ & $6-19 * 01$ & $6 * 02$ & $1-9 * 01$ & $5 * 01$ \\
107 & $6-1 * 01$ & $6-19 * 01$ & $6 * 02$ & $1-9 * 01$ & $5 * 01$ \\
\hline 206 & $1-69 * 12$ & $2-8 * 01$ & $6 * 02$ & $1-12 * 01$ & $4 * 01$ \\
217 & $1-69 * 12$ & $2-8 * 01$ & $4 * 02$ & $4-1 * 01$ & $4 * 01$ \\
218 & $1-69 * 01$ & $3-22 * 01$ & $4 * 02$ & $1 G L V 2-14 * 01$ & IGLJ201 \\
220 & $1-69 * 01$ & $2-15 * 01$ & $4 * 02$ & $1-33 * 01$ & $4 * 01$ \\
221 & $1-69 * 01$ & $6-19 * 01$ & $4 * 02$ & $3-15 * 01$ & $1 * 01$ \\
223 & $1-69 * 12$ & $2-15 * 01$ & $6 * 02$ & $3-15 * 01$ & $3 * 01$ \\
226 & $1-69 * 12$ & $3-10 * 01$ & $1 * 01$ & $3-15 * 01$ & $3 * 01$ \\
228 & $1-69 * 01$ & $3-3 * 01$ & $6 * 02$ & $1-33 * 01$ & $4 * 01$ \\
\hline
\end{tabular}

Gene segment usage and allele usage was identified using the IMGT V-QUEST tool. 
Supplementary Table 2. Kinetics and affinity of the HLA-DQ2.5:DQ2.5-glia- $\alpha 2-s p e c i f i c$ antibodies.

\begin{tabular}{|c|c|c|c|c|c|c|}
\hline \multirow[b]{2}{*}{ Clone } & \multicolumn{4}{|c|}{ Kinetics and affinity } & \multicolumn{2}{|c|}{ Steady state ${ }^{c}$} \\
\hline & kon $\left(M^{-1} s^{-1}\right)$ & $\mathrm{K}_{\text {off }}\left(\mathrm{s}^{-1}\right)$ & $\mathrm{K}_{\mathrm{D}}(\mathrm{M})$ & SE KD (M) & $K_{D}(M)$ & SE KD (M) \\
\hline Fab $206^{a}$ & $1.02 \times 10^{6}$ & 0.2291 & $2.24 \times 10^{-7}$ & $2.25 \times 10^{-7}$ & $2.54 \times 10^{-7}$ & $2.70 \times 10^{-9}$ \\
\hline Fab $206^{b}$ & $1.077 \times 10^{6}$ & 0.2462 & $2.280 \times 10^{-7}$ & & NA & NA \\
\hline Fab 2.B11 ${ }^{b}$ & $2.208 \times 10^{6}$ & $3.285 \times 10^{-4}$ & $1.488 \times 10^{-10}$ & & NA & NA \\
\hline Fab 3.C11 ${ }^{b}$ & $1.669 \times 10^{6}$ & $6.967 \times 10^{-5}$ & $4.174 \times 10^{-11}$ & & NA & NA \\
\hline Fab 3.C $7^{b}$ & $2.006 \times 10^{6}$ & $7.111 \times 10^{-4}$ & $3.544 \times 10^{-10}$ & & NA & NA \\
\hline Fab 3.D8 ${ }^{b}$ & $1.545 \times 10^{6}$ & $1.729 \times 10^{-3}$ & $1.119 \times 10^{-9}$ & & NA & NA \\
\hline Fab 3.F6 ${ }^{b}$ & $8.096 \times 10^{5}$ & $1.225 \times 10^{-3}$ & $1.513 \times 10^{-9}$ & & NA & NA \\
\hline $\mathrm{Fab} 12 . \mathrm{FG}^{\mathrm{b}}$ & $8.039 \times 10^{5}$ & $7.456 \times 10^{-4}$ & $9.275 \times 10^{-10}$ & & NA & NA \\
\hline Fab 3.C11 & $1.190 \times 10^{6}$ & $1.126 \times 10^{-4}$ & $9.462 \times 10^{-11}$ & $3.10 \times 10^{-7}$ & NA & NA \\
\hline Fab 3.C11 & $1.387 \times 10^{6}$ & $1.118 \times 10^{-4}$ & $8.064 \times 10^{-11}$ & $1.30 \times 10^{-7}$ & NA & NA \\
\hline Fab 3.C11 & $1.335 \times 10^{6}$ & $1.206 \times 10^{-4}$ & $9.039 \times 10^{-11}$ & $1.20 \times 10^{-7}$ & NA & NA \\
\hline
\end{tabular}

Kinetics were determined by fitting data to a 1:1 Langmuir binding model.

a Determined from single cycle kinetics.

${ }^{b}$ Determined from one concentration of protein in off-rate screening. $K_{D} S$ obtained with this method disregarded when calculating average values.

NA, not available 
Supplementary Table 3. Data collection and refinement statistics.

\begin{tabular}{|c|c|}
\hline Wavelength & 0.95372 \\
\hline Resolution range & $47.03-2.4(2.486-2.4)$ \\
\hline Space group & P 212121 \\
\hline Unit cell a, b, c ( $\AA$ ) & 91.847143 .047170 .153 \\
\hline$\alpha, \beta, \gamma$ & 909090 \\
\hline Total reflections & 176197 (17433) \\
\hline Unique reflections & $88213(8724)$ \\
\hline Multiplicity & $2.0(2.0)$ \\
\hline Completeness (\%) & 99.93 (99.91) \\
\hline Mean I/sigma(I) & $8.78(2.04)$ \\
\hline Wilson B-factor & 37.16 \\
\hline R-merge & $0.07157(0.5562)$ \\
\hline R-meas & $0.1012(0.7866)$ \\
\hline R-pim & $0.07157(0.5562)$ \\
\hline $\mathrm{CC} 1 / 2$ & $0.993(0.633)$ \\
\hline $\mathrm{CC}^{*}$ & $0.998(0.88)$ \\
\hline Reflections used in refinement & $88212(8720)$ \\
\hline Reflections used for R-free & $1822(181)$ \\
\hline R-work & $0.1762(0.2701)$ \\
\hline R-free & $0.2124(0.2877)$ \\
\hline CC(work) & $0.963(0.816)$ \\
\hline CC(free) & $0.959(0.852)$ \\
\hline Number of non-hydrogen atoms & 13695 \\
\hline macromolecules & 12599 \\
\hline ligands & 281 \\
\hline solvent & 815 \\
\hline Protein residues & 1607 \\
\hline RMS(bonds) & 0.006 \\
\hline RMS(angles) & 0.83 \\
\hline Ramachandran favored (\%) & 97.41 \\
\hline Ramachandran allowed (\%) & 2.59 \\
\hline Ramachandran outliers (\%) & 0.00 \\
\hline Rotamer outliers (\%) & 1.19 \\
\hline Clashscore & 3.29 \\
\hline Average B-factor & 48.89 \\
\hline macromolecules & 48.32 \\
\hline ligands & 81.78 \\
\hline solvent & 46.39 \\
\hline Number of TLS groups & 36 \\
\hline
\end{tabular}

Statistics for the highest-resolution shell are shown in parentheses. 